\title{
Making Headway: The Roles of Hox Genes and Neural Crest Cells in Craniofacial Development
}

\author{
Paul A Trainor \\ Stowers Institute for Medical Research, 1000 East $50^{\text {th }}$ Street, Kansas City, MO 64110 \\ E-mail: pat@stowers-institute.org; www.stowers-institute.org
}

Received April 11, 2002; Revised June 11, 2002; Accepted June 19, 2002; Published April 14, 2003

Craniofacial development is an extraordinarily complex process requiring the orchestrated integration of multiple specialized tissues such as the surface ectoderm, neural crest, mesoderm, and pharyngeal endoderm in order to generate the central and peripheral nervous systems, axial skeleton, musculature, and connective tissues of the head and face. How do the characteristic facial structures develop in the appropriate locations with their correct shapes and sizes, given the widely divergent patterns of cell movements that occur during head development? The patterning information could depend upon localized interactions between the epithelial and mesenchymal tissues or alternatively, the developmental program for the characteristic facial structures could be intrinsic to each individual tissue precursor. Understanding the mechanisms that control vertebrate head development is an important issue since craniofacial anomalies constitute nearly one third of all human congenital defects. This review discusses recent advances in our understanding of neural crest cell patterning and the dynamic nature of the tissue interactions that are required for normal craniofacial development.

KEY WORDS: Hox genes, neural crest cells, craniofacial development, mouse, chick, embryo, branchial arch, pharyngeal arch, plasticity, neural tube, rhombomere, segmentation, mesoderm, ectoderm, endoderm, evolution

DOMAINS: genetics (mouse), embryology, neuroscience, developmental biology, evolutionary genetics

\section{ORGANISATION OF THE HINDBRAIN AND ITS INFLUENCE ON CRANIOFACIAL DEVELOPMENT}

The vertebrate hindbrain is one key source of patterning information and it exerts a profound influence on craniofacial development. During early vertebrate embryo development, the 
hindbrain becomes transiently subdivided into seven contiguous cell lineage restricted compartments called rhombomeres (r) (Fig. 1)[1]. Each rhombomere adopts a distinct set of molecular and cellular properties including restrictions in cell mixing and gives rise to unique regions of the mature adult brain[2,3,4,5,6,7,8,9]. The segmental organization of the hindbrain presages the establishment of an anatomical and functional registration between individual rhombomeres, cranial ganglia, branchiomotor nerves, and the migration pathways of cranial neural crest cells into the branchial arches[10,11,12].

In chick embryos, the formation and disposition of motor neurons conforms to a twosegment periodicity. The trigeminal (Vth), facio-acoustic (VIIth), and glossopharyngeal (IXth) motor nerves innervate the first three branchial arches, respectively. Although each nerve is derived from neurons born in multiple rhombomeres, the axons leave the hindbrain through exit points contained only within the even-numbered rhombomeres (Fig. 1)[10,11]. Similar to its influence on cranial nerve patterning, the rhombomeric organization of the hindbrain also influences the pathways of cranial neural crest cell migration. The hindbrain gives rise to the majority of cranial neural crest cells which migrate ventrolaterally in three discrete segmental streams adjacent to the even-numbered rhombomeres. The streams of cranial neural crest cells follow a subectodermal route over the surface of the cranial mesoderm and populate the first, second, and third branchial arches, respectively, in keeping with their craniocaudal origins (Fig. 1) $[13,14,15,16]$. Although almost the entire cranial neural tube generates neural crest cells, it appears that substantially less neural crest cells delaminate from the odd rhombomeres compared with the even-numbered rhombomeres. In chick embryos, this phenomenon is believed to be associated with odd rhombomere specific apoptosis of neural crest precursors[17,18,19]. Rather than delaminating and migrating laterally like the rest of the hindbrain neural crest, lineage tracing and time-lapse analyses in numerous vertebrates, show that $\mathrm{r} 3$ - and $\mathrm{r} 5$-derived neural crest cells migrate both rostrally and caudally joining the even-numbered streams as they contribute to the proximal most regions of the branchial arches[12,14,15,16,20,21,22,23]. Gene mutationswhich disrupt the segmental patterning of the hindbrain — result in fusions of the cranial ganglia, branchiomotor defects, and abnormal patterns of cranial neural crest cell migration[24,25,26,27,28,29,30,31,32,33]. Therefore, the segmental organization of the hindbrain is essential for establishing the foundations of head development and is a conserved strategy used by vertebrates to ensure proper craniofacial morphogenesis.

\section{MECHANISMS FOR SEGMENTATION OF THE HINDBRAIN}

The establishment of segment identity and the maintenance of organized patterns of gene expression during hindbrain development requires the restriction of cell intermingling between adjacent segments. Cells with similar adhesive properties such as those from odd or even rhombomeres display a preferential association[34,35]. Consequently, it was hypothesized that segregating the distinct cell populations was facilitated by a hierarchy of cell adhesion interactions[36]. The appearance of restricted domains of gene expression in the hindbrain coincides with rhombomere partitioning and the adoption of neural character (Fig. 1). Numerous genes including transcription factors, signalling molecules, membrane and nuclear receptors are all dynamically expressed in segmentally restricted patterns during hindbrain development (reviewed in $[37,38,39])$. Some genes are expressed in single rhombomeres, a few are confined to pairs of rhombomeres, while others are found only at rhombomere boundaries. Regulatory and mutational analyses in mice and other vertebrate species have helped to uncover the molecular and cellular mechanisms involved in subdividing the hindbrain into rhombomeres.

Restrictions in cell mixing are crucial for establishing the unique segmental identities of each rhombomere and the Eph family of receptor tyrosine kinases and their ligands, the ephrins, play key roles in this process[40]. The Eph receptors and their ephrin ligands are expressed in 
mutually exclusive domains in the hindbrain such that each receptor and its associated ligand is expressed in an alternate, nonoverlapping pattern in adjacent rhombomeres (Fig. 1)[40,41,42,43]. For example, during the 8.0-10.5 days postcoitum (dpc) period of mouse embryonic development, $E p h B$ receptors are expressed in odd-numbered rhombomeres and their corresponding ephrin $B$ ligands are expressed in the adjacent even-numbered rhombomeres. In addition to the EphB receptors, the receptors EphA2 and EphA4 are also segmentally expressed in hindbrain rhombomeres (Fig. 1). The mosaic activation of Eph receptors or their ephrin ligands in the hindbrain leads to cell sorting at the boundaries of odd and even rhombomeres, respectively. This suggests that bidirectional signalling at rhombomere boundaries restricts cell intermingling $[44,45]$. Therefore bipartite Eph/ephrin contact-mediated repulsion maintains interrhombomeric boundaries which are essential for establishing the hindbrain compartments as units of cell lineage restriction.

\section{SPECIFYING SEGMENTAL IDENTITY IN THE HINDBRAIN}

Genetic analyses in several vertebrate species have shown that Hox genes are essential for specifying segmental identity in the developing hindbrain. The Hox gene family comprises a set of developmentally regulated transcription factors that are characterized by a conserved DNA binding motif called the homeobox. Hox genes are organized into a single chromosomal cluster in invertebrates, in contrast to higher vertebrates such as the mouse which have 39 Hox genes, organized into four distinct chromosomal clusters (Hoxa-Hoxd) located on different chromosomes[46]. This arrangement arose during evolution from a single ancestral homeobox as a consequence of duplication and divergence[47]. The most striking feature of the organization of Hox gene family members is the spatial and temporal colinearity, which confers positional information along the body axis[46,48,49,50]. Genes located nearer to the 3 ' end of the cluster are expressed earlier and more anteriorly during development than those located nearer the 5, end, such that Hox genes exhibit nested domains of expression along the anterior-posterior (A-P) axis of the neural tube. Only the 3' members of each complex (paralogue groups 1-4) are expressed in the vertebrate hindbrain and these Hox genes exhibit dynamic patterns of expression during hindbrain development (Fig. 1)[51].

Hoxal and Hoxbl are initially expressed in the neural tube up to the presumptive r3/4 boundaries, but as Hoxal expression regresses, Hoxbl expression becomes confined to $\mathrm{r} 4$ by $8.5 \mathrm{dpc}$ during mouse embryo development[52,53,54]. Hoxa2 expression is initiated in the neural epithelium at $7.5 \mathrm{dpc}$ and by $8.5 \mathrm{dpc}$ it is uniformly expressed up to the $\mathrm{r} 1 / \mathrm{r} 2$ boundary[51]. Shortly thereafter Hoxa 2 becomes expressed at significantly higher levels in r3 and r5[55]. In contrast, Hoxb2 is expressed up to the $\mathrm{r} 2 / \mathrm{r} 3$ boundary around the same time, but its expression levels are subsequently upregulated in r3, r4, and r5[56,57]. Group 3 (Hoxa3, Hoxb3, Hoxd3) genes are expressed anteriorly up to the $\mathrm{r} 4 / \mathrm{r} 5$ boundary, with Hoxa 3 exhibiting upregulation in $\mathrm{r} 5$ and r6 and Hoxb3 being similarly upregulated in r5[58,59]. In contrast, Hoxd3 is expressed at lower levels in $\mathrm{r} 5$ than more posterior regions. Group 4 genes (Hoxa4, Hoxb4, Hoxd4, and Hoxc4) are generally expressed up to the $\mathrm{r} 6 / \mathrm{r} 7$ boundary by $9.5 \mathrm{dpc}$, however their precise anterior limits vary slightly (Fig. 1)[60,61]. 


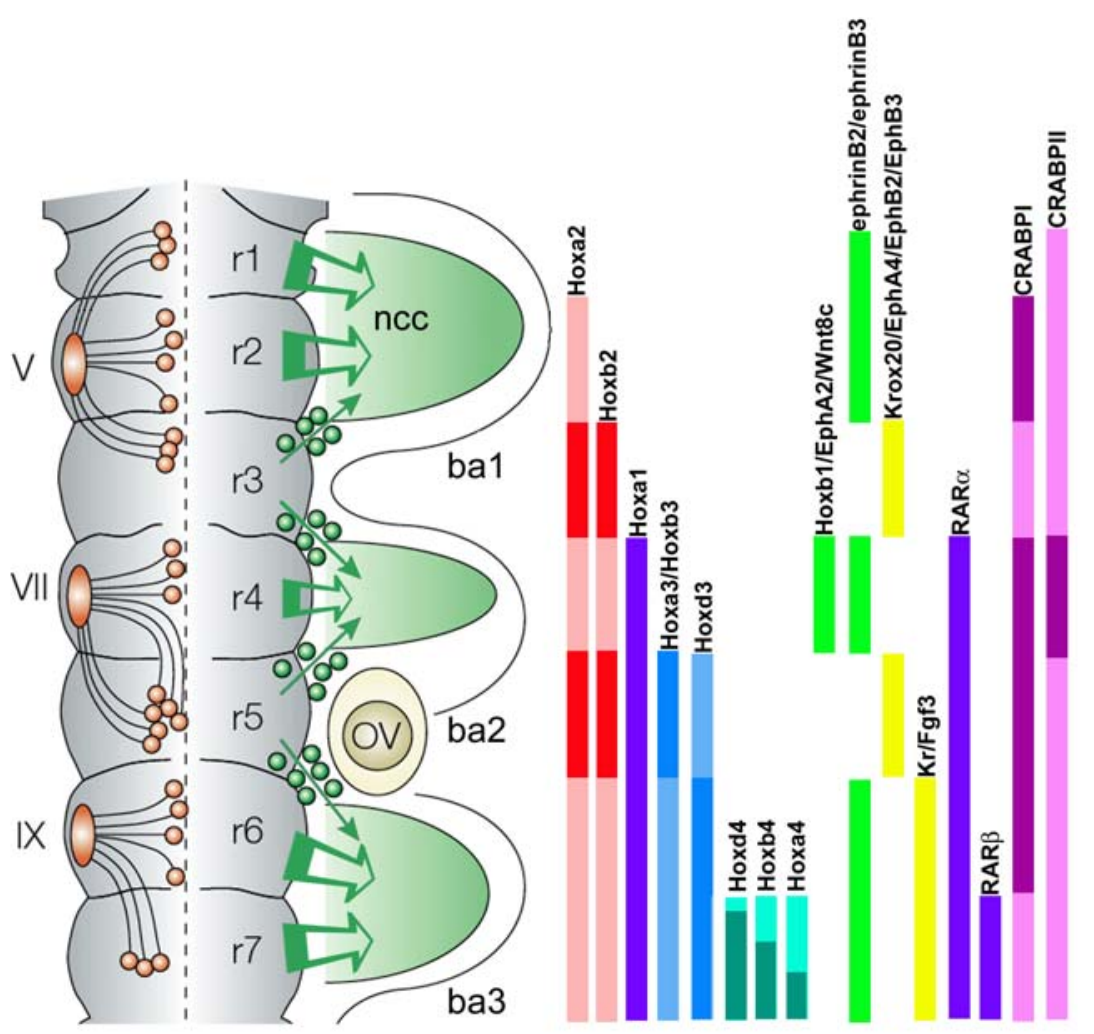

FIGURE 1. Segmentation of the hindbrain, motor nerves, and pathways of neural crest cell (ncc) migration. The vertebrate hindbrain becomes subdivided into 7 transient rhombomeres (r) which presages the segmental organization of the branchiomotor nerves, III (trigeminal), V (facial), and VII (glossopharyngeal) and their innervation of the first (ba1), second (ba2), and third (ba3) branchial arches, respectively. Although the cell bodies (small red circles) that make up each branchiomotor nerve are derived from multiple rhombomeres, their axons project and leave the neural tube only from exit points contained within the even numbered rhombomeres (large red circles). Neural crest cells derived from the hindbrain (large green arrows) migrate ventrolaterally in three segmental streams adjacent to the even-numbered rhombomeres and into the branchial arches. Neural crest cells derived from the odd-numbered rhombomeres do not migrate laterally, rather they migrate anteriorly or posteriorly to join the even-numbered neural crest streams. The hindbrain segmentation process which establishes each rhombomere as a unit of cell lineage and the subsequent imposition of cell fate identity corresponds with the activation of expression, of genes from multiple families, such as Hox, Eph/ephrin, RAR and $C R A B P$ families. The patterns of gene expression are extremely dynamic and only the primary pattern for each gene between $8.5-$ $10.5 \mathrm{dpc}$ is shown here. The only exception is Hoxal which is expressed up to the presumptive r $3 / 4$ boundary at $7.5 \mathrm{dpc}$ but is subsequently switched off before rhombomere formation. OV, otic vesicle.

\section{GENETIC CONTROL OF HOX GENE EXPRESSION AND HINDBRAIN PATTERNING}

Hox genes are an integral part of the process specifying regional variation in the developing hindbrain, however little is known of the cascade of events that regulate their expression or the process of segmentation itself. In general, Hox gene expression patterns are generated in two distinct phases: establishment followed by maintenance. The mechanism by which Hox genes become expressed at higher relative levels in specific rhombomeres is independent from the process that generates the more generalized expression patterns along the length of the neural tube. Positional values along the A-P axis appear to be conferred on the rhombomeres by differential Hox gene expression however it is not entirely clear how appropriate levels of expression are attained within individual rhombomeres. The observation that other genes were 
expressed in the hindbrain in segmentally restricted patterns overlapping with the patterns of $H o x$ gene expression implied that these genes were involved in regulating Hox gene expression and ultimately controlling hindbrain development. Currently, there are three upstream candidate regulators of Hox gene expression during hindbrain development and they are the transcription factors Krox20 and kreisler and the vitamin A derivative, retinoic acid.

\section{KROX20 REGULATION OF HOX GENES}

Krox20 encodes a protein with three $\mathrm{C}_{2} \mathrm{H}_{2}$-type zinc fingers and was initially identified as an immediate early response gene in serum stimulated fibroblasts[62]. During early embryonic development, Krox 20 is expressed in $\mathrm{r} 3$ by the $8.0 \mathrm{dpc}$ stage, followed by r5, which occurs prior to the appearance of lineage-restricted compartments in the hindbrain (Fig. 1)[2]. Krox20 acts as a transcription factor by binding to a specific DNA sequence and directly regulates Hoxa2, Hoxb2, Hoxb3, and EphA4 through cis-acting sequences in the 5' flanking region of these genes[63,64]. Krox20 therefore is an essential component of the upstream regulatory cascade governing hindbrain segmentation. The overlapping expression patterns of Krox20 and EphA4 expression suggests that transcriptional control and cell-cell signalling could be coupled together.

\section{KREISLER REGULATION OF HOX GENES}

The kreisler mouse was identified due to its circling behavior, a phenotype, which is usually associated with inner ear defects[65]. Kreisler expression is initiated at $8.5 \mathrm{dpc}$ in the prospective $\mathrm{r} 5$ territory and is later expressed in $\mathrm{r} 5$ and $\mathrm{r} 6$ after which it is quickly downregulated in both rhombomeres (Fig. 1)[66]. The gene responsible for the kreisler mutation has been positionally cloned, and is a member of the Maf oncogenic family of b-zip (basic domain-leucine zipper) transcription factors[66]. The analysis of gene expression in kreisler mutant embryos strongly suggested it might play a direct role in the transcriptional regulation of genes important for hindbrain and inner ear development, particularly the Hoxa3 and Hoxb3 genes that are upregulated in r5 and r6. Analyses of the regulatory regions of Hoxa 3 and Hoxb3 in mouse and chick embryos have shown that both these genes are under the direct control of the product of the kreisler gene[32].

\section{RETINOID REGULATION OF HOX GENE EXPRESSION}

Retinoids constitute a group of vitamin A-derived signalling molecules that are involved in specifying the CNS[67,68]. Exogenous vitamin A metabolites such as retinoic acid (RA), when applied to embryos during the early stages of development, cause severe craniofacial malformations, particularly within the hindbrain and branchial arch region[67,69,70,71,72]. Cellular retinoid-binding proteins (CRBPI and $I I, C R A B P I$ and $I I)$ are thought to control regional RA concentration and hence facilitate its function[73]. $C R B P$ expression is confined primarily to the floor plate, where it binds retinol taken up from the blood and CRABPI is expressed in the mouse hindbrain in $\mathrm{r} 4-6$ and at lower levels in $\mathrm{r} 2$ at $9.5 \mathrm{dpc}[74,75]$. CRABPII is also expressed at high levels in the hindbrain and its expression extends posteriorly along the length of the neural tube (Fig. 1)[76,77]. CRABPs therefore may be responsible for sequestering RA and thus limiting the amount of RA available to the nuclear RA receptors ( $R A R \mathrm{~s}$ and $R X R \mathrm{~s})$ that recognize particular sequence motifs within target genes called retinoic acid response elements (RAREs)[78,79]. There are three genes in each of the $R A R$ and $R X R$ families (a, b, and g). $R A R a$ is expressed up to the $\mathrm{r} 3 / 4$ border while $R A R b$ is expressed in the neural tube to an anterior limit 
coinciding with the $\mathrm{r} 6 / 7$ border[80,81]. $R X R a$ and $R X R b$ are expressed fairly uniformly throughout the entire hindbrain neuroepithelium (Fig. 1)[82,83]. Not all the family members however are expressed in the hindbrain

RA is the strongest candidate as an overall mediator of nested Hox gene expression. Excess RA causes both an anterior shift in Hox gene expression and an anterior to posterior transformation of regional fate[50,67,71,72,84,85,86,87,88,89,90,91,92]. Conversely, the suppression of RA signalling by the expression of dominant-negative retinoid receptors, results in anteriorization $[93,94,95,96]$. Hox genes contain the molecular machinery for responding directly to retinoid signalling $[97,98,99,100,101,102,103]$. The group 1 paralogs Hoxal and Hoxb1 contain 3' cis-regulatory RARE as do the group 4 paralogs Hoxa4, Hoxb4 and Hoxd4. Hoxal and Hoxb1 are among the first Hox genes to be activated during development and their expression is initiated during gastrulation in response to RA, first in the newly formed mesoderm, and then in the overlying ectoderm up to a sharp anterior limit at the presumptive rhombomere $3 / 4$ hindbrain border. As Hoxal expression subsides, retinoids make a second input into Hoxbl regulation by refining its domain of expression to a single rhombomere segment ( $\mathrm{r} 4)$. This second input involves a negative pathway that is employed to abolish expression in the neighboring odd rhombomeres $\mathrm{r} 3$ and $\mathrm{r} 5[99,100]$. The site for repression is located within the 5' flanking region of the Hoxbl gene and includes another RARE, point mutations in which permit expression to spread into the neighboring rhombomeres. The application of exogenous retinoids at $7.5 \mathrm{dpc}$ results in the ectopic activation of Hoxal, Hoxbl, and Hoxa2 in more anterior tissues which is consistent with RAs perceived role as having a posteriorizing effect on the CNS. The group 4 paralogs Hoxa4, Hoxb4, and Hoxd4 genes are also capable of responding to RA but only when administered between $8.5-9.5 \mathrm{dpc}[61,92,104]$. Therefore retinoids (or more specifically RA acting via its receptor molecules [RARs and $R X R \mathrm{~s}]$ ) are crucial in the establishment phase of Hox gene expression and the specification of segmental identity in the hindbrain.

\section{HOX GENE AUTO AND CROSS-REGULATION}

A unique property of the group 1 paralogs is displayed by the Hoxbl gene which after its establishment phase, maintains high levels of expression in $\mathrm{r} 4[52,54]$. The continued expression or maintenance phase of Hoxb1 in $\mathrm{r} 4$ does not involve RA but is achieved through a conserved autoregulatory loop involving Hoxbl together with an unspecified $P b x$ family protein[105]. Despite the similarities in expression and regulation between various Hox gene paralogs, there is frequently variation in their relative levels within specific segments. For example, of the group 2 homologs simultaneously expressed in $\mathrm{r} 4$, Hoxb2 is upregulated, but in contrast, Hoxa 2 is not. This type of differential expression suggests that in even-numbered rhombomeres these two genes have distinct modes of regulation. Consequently it has been shown in vitro that Hoxbl is able to bind to Hoxb2 in a cross-regulatory interaction[57]. A great deal of our understanding of Hox cross-regulation has come from analyses of the cis-regulatory regions of the group 4 paralogs, Hoxb4 and Hoxd4, which have domains of expression that partially overlap and map to the r6/7 junction[106]. Similar to Hoxb1, Hoxb4, and Hoxd4 are also capable of auto-regulation. These studies highlight the importance of auto-regulatory and cross-regulatory mechanisms for the functional maintenance of Hox gene expression and specification of rhombomere identity during vertebrate hindbrain development. 


\section{HOX GENE SPECIFICATION OF SEGMENTAL IDENTITY AND MUTATIONAL ANALYSES}

By analogy to their Drosophila counterparts, it was predicted that Hox genes would play essential roles in regulating the identity of individual hindbrain segments[4,51,52] and this has now been confirmed through null mutation and ectopic expression analyses for most of the 3 ' members of the Hox gene family. Hoxal null mutants die at birth from anoxia and exhibit marked defects in the inner ear and in specific cranial nerve components[24]. The embryonic phenotype is characterized by a reduction in the size of $\mathrm{r} 4$ and the partial deletion of $\mathrm{r} 5$ as revealed by the diminished expression of Hoxb1 in r4, and of Krox 20 and Fgf3 in r5, and this may account for the absence of facial nerve and abducens nerve motor neurons. A second independently produced Hoxal null mutant exhibits a slightly different phenotype, in which there is a complete absence of rhombomere segmentation, including the first three rhombomeres where Hoxal is never expressed[25]. Nevertheless, the null mutant phenotypes indicate that the Hoxal gene product is necessary for the proper segmentation of r4-6. In addition the activity of Hoxal appears to be critical for the specification of rhombomeric identity because ectopic expression of this gene in $\mathrm{r} 2$ results in the adoption of gene expression typical of $\mathrm{r} 4[107,108]$. Hoxal is therefore critical to both hindbrain segmentation and specification.

Hoxb1 mutants exhibit changes in segmental identity; however, in contrast to the Hoxal mutants they show no segmentation defects[30,31]. Molecular analyses indicate that the patterning of $\mathrm{r} 4$ is initiated properly but not maintained in Hoxb1 mutant embryos. Rhombomere 4 specific markers such as $W n t 8 c$ and $C R A B P 1$ fail to be upregulated and genetic markers of r2 are ectopically expressed in $\mathrm{r} 4$ suggesting that the identity of $\mathrm{r} 4$ has been transformed[31]. Consequently, the facial branchiomotor neurons (FBM) and contralateral vestibular acoustic efferent (CVA) neurons, which are specific to $\mathrm{r} 4$ are incorrectly specified. Both sets of neurons fail to migrate into the correct position leading to a loss of the facial motor nerve. These results demonstrate that as part of its role is in maintaining rhombomere identity, Hoxbl is involved in controlling migratory properties of motor neurons in the hindbrain. Ectopic expression of Hoxb1 in $\mathrm{r} 2$ of chick embryos transforms the character of this segment into that of rhombomere 4[109]. These gain of function experiments suggest that Hoxbl is involved in specifying individual segmental identity.

The phenotypes of individual Hoxal and Hoxb1 loss of function (null) mutations suggest that these genes play distinct roles in hindbrain development. However, Hoxal/Hoxb double mutants exhibit a surprising range of phenotypes that are absent from the individual mutants, indicating that establishment of $\mathrm{r} 4$ identity and patterning of the VII-XI cranial nerves requires extensive synergy between Hoxal and Hoxb1[110,111]. In the absence of both genes, a territory appears in the region of r4, however EphA2 (which is one of the earliest markers of r4) fails to be activated. Not only does EphA2 lie downstream of Hoxal and Hoxb1 in the genetic cascade that regulates hindbrain segmentation and specification, but it suggests that in the double mutants there is a failure to initiate rather than maintain the specification of $\mathrm{r} 4$ identity. The double mutants also revealed that Hoxal and Hoxbl work synergistically to initiate the r4 restricted expression domain of Hoxb1. Hoxal seems to play a role during the establishment phase of Hox gene expression by activating the $\mathrm{r} 4$ enhancer of Hoxbl. This is achieved through 3' RARE pararegulatory interactions. Hoxal however, is unable to participate in the long-term maintenance of Hoxb1 expression because it is not expressed at these later stages. Therefore in concert with RA, pararegulatory interactions between Hoxal and Hoxbl initiates Hoxbl expression in r4, after which time, the Hoxb1 autoregulatory mechanism kicks in to ensure that high Hoxbl expression levels are maintained. Hoxbl also functions in a direct cross-regulatory manner to upregulate Hoxb2 expression in $\mathrm{r} 4$. Therefore Hoxb1 utilizes auto-, para-, and cross-regulatory mechanisms as part of its role in maintaining $\mathrm{r} 4$ identity and regulating facial motor neuron patterning. 
Hoxa 2 is the only Hox gene to be expressed in $\mathrm{r} 2$ and is the most anteriorly expressed of all the Hox genes[112]. Null mutations in Hoxa2 result in homeotic transformations of the second arch neural crest derived elements into first arch derivatives and subsequently perinatal lethality[113]. The hindbrain is also affected to the extent that the segmental identities of $\mathrm{r} 2$ and r3 are altered. EphA4 expression is selectively abolished in r2, indicating that Hoxa2 is required for the maintenance of EphA4 expression in r2. Consequently, the alar territories of $\mathrm{r} 2$ and $\mathrm{r} 3$ are reduced and there is a concomitant expansion of $\mathrm{r} 1$. In addition, the trigeminal motor axons derived from $\mathrm{r} 2$ and $\mathrm{r} 3$ migrate caudally and exit the hindbrain from the $\mathrm{r} 4$ facial nerve exit point rather than their normal exit point in r2. Since Hoxa2 is the only Hox gene expressed in r2, these results suggest that the identity of $\mathrm{r} 2$ has been transformed and that it now resembles $\mathrm{r} 4$. Hoxa 2 therefore not only acts as a selector gene for second arch mesenchymal neural crest cells but also plays a fundamental role in rostral hindbrain patterning by establishing the identity of $r 2$ and by influencing the migration of $\mathrm{r} 2 / 3$ derived motor axons.

In contrast to Hoxa 2 mutants, the loss of Hoxb2 locus does not result in abnormalities to the segmental anterio-posterior organization of the developing hindbrain[114]. Rhombomeres 3 and 5 develop normally, despite the absence of Hoxb2 upregulation in these rhombomeres. Phenotypic changes affecting dorsoventral (D-V) patterning however were observed in the hindbrain such that $\mathrm{r} 4$ specific neural precursors now closely resembled those originating in $\mathrm{r} 2$. This suggests that a subset of ventral motor neuron precursors may be incorrect specified. In addition, development of the somatic motor component of the facial nerve is impaired in Hoxb2 null mutants, which is reminiscent of the phenotype described in the Hoxb1 mutants. Hoxb2 therefore plays an important role in regulating the generation and/or fate of subsets of $\mathrm{r} 4$ motor neuron progenitors.

The generation of Hoxa2/Hoxb2 double mutants revealed that synergistically these genes play an important role in coupling A-P and D-V patterning[115]. Hoxa2 and Hoxb2 play distinct roles in mediating hindbrain neurogenesis. Hoxa2 regulates development in the alar and dorsal basal plates of $\mathrm{r} 2$ and $\mathrm{r} 3$ whereas Hoxb2 is essential for motorneuron development in the ventral region of $\mathrm{r} 4$. In the double mutants, functional synergy between Hoxa 2 and Hoxb2 in $\mathrm{r} 3$ has been suggested based on the absence of a ventral interneuron subtype, which is developmentally normal in both the single mutants. In addition there also appears to be a joint requirement for Hoxa 2 and Hoxb2 in patterning inter-rhombomeric boundaries. Despite the fact that the normal number of hindbrain segments form in the double mutants, boundary formation between r1-4 is nonexistent. Therefore these results indicate that Hoxa2 and Hoxb2 differentially control alar and basal plate development within distinct rhombomeres. Perhaps more importantly this provides a link between Hox mediated patterning along the A-P axis and neurogenesis along the D-V axis and can account mechanistically for the generation of neurons at reproducible positions within hindbrain segments.

A targeted mutation in the Hoxa3 gene results primarily in mesenchymal neural crest defects[116]. The Hoxa3 null mutant mice are athymic, aparathyroid, and have throat cartilage malformations. In addition, the loss of Hoxa3 leads to defects in the formation of the IXth cranial nerve and also fusions between the IXth and Xth nerves. Examination of the cranial nerves in Hoxb3-/- embryos revealed similar cranial ganglia defects but at a lower penetrance than in the Hoxa 3 mutants[117]. In contrast, the cranial nerves in the Hoxd3-/- embryos are completely normal[118,119]. Therefore at least two of the group 3 paralogs play essential roles in formation of the IXth cranial ganglion. Double mutants (Hoxa3/Hoxb3, Hoxa3/Hoxd3, and Hoxb3/Hoxd3) were subsequently generated and in Hoxb3/Hoxd3 double mutants there was a marked increase in the penetrance of the IXth cranial ganglion defects relative to that observed in the Hoxb3 single mutant $[118,119,120]$. This increase in penetrance shows that Hoxd3 plays a synergistic role with Hoxb3 in cranial nerve development even though the Hoxd3 single mutant does not show a defect in these structures. 


\section{KROX20 NULL MUTATIONS}

The necessity for coupling cell identity and cell lineage restrictions in order to generate sharply restricted and specified segmental domains during hindbrain development is highlighted in the phenotype of Krox20 null mutants. Mice homozygous for a targeted mutation in Krox20 die shortly after birth and exhibit fusions of the trigeminal ganglion with facial and vestibular ganglia as a consequence of the profound perturbation of hindbrain morphogenesis[26,27,121]. Although the presumptive territories of rhombomeres 3 and 5 do form during the very early stages of hindbrain development, these two rhombomeres are not maintained and their structural derivatives are subsequently eliminated. Consistent with the interactions unveiled by transgenic analyses between Krox20 and Hoxa2, Hoxb2, Hoxb3, and EphA4, no upregulation of these three genes was observed in Krox20 mutants. Therefore Krox20 is a key regulator of gene expression and segmentation in the developing hindbrain.

\section{KREISLER mutants}

The kreisler mutation is not a null allele, but a regulatory mutation affecting those enhancer elements responsible for the hindbrain domain of expression of the gene[66]. The primary defect in kreisler mutant embryos is a disruption of segmentation in the otic region of the hindbrain, whereby the rhombomeric borders that normally demarcate $\mathrm{r} 4,5$, and 6 are absent[32,65,122]. Consequently the normal expression domains of $F g f 3$ and $C R A B P I$ and the upregulation of Hoxa 3 in r6 are absent. Although Krox20 expression in presumptive r3 is present, the posterior band associated with $\mathrm{r} 5$ is missing. Similarly, the normal expression domains of Hoxb2, Hoxb3, and Hoxb4 in $\mathrm{r} 5$ are also abolished. Analysis of patterns of expression of EphA7 and ephrinB2 indicate that only a single segment correlating with $\mathrm{r} 5$ is missing. Therefore the segmentation defect associated with the kreisler mutant is a specific loss of $\mathrm{r} 5$ and although an $\mathrm{r} 6$ territory does form, it fails to mature[32]. Through direct regulation of Hox genes, kreisler controls segmental identity and this is further evidenced by the ectopic activation of kreisler in $\mathrm{r} 3$ which transforms the character of this territory into that of r5[123]. The role played by kreisler in hindbrain patterning is therefore analagous to Krox20 because rather than being restricted to a single patterning aspect, kreisler is involved at several different levels including establishment and maintenance of A-P identity in addition to segment specification.

Clearly hindbrain segmentation in the form of cell lineage restrictions and compartmentalization is coupled with the acquisition of specific cellular identities. The studies described above illustrate that Hox genes function in many steps of hindbrain segmentation process particularly in specifying segmental identity. Consequently hindbrain segmentation and rhombomere specification plays important roles in patterning the craniofacial structures of neural crest origin.

\section{CRANIAL NEURAL CREST CELLS AND THE PREPROGRAMMING MODEL FOR CRANIOFACIAL DEVELOPMENT}

Neural crest cells were so named because of their formation along almost the entire axis of vertebrate embryos at the crest of the closing neural folds. This region corresponds to the interface or junction between the non-neural ectoderm (presumptive epidermis or surface ectoderm) and the neural plate (neuroepithelium), a region commonly referred to as the neural plate border (Fig. 2). Neural crest cell induction requires contact-mediated interactions between the surface ectoderm and neuroepithelium and importantly, each of these tissues contributes to the neural crest cell lineage[124]. BMP signalling is thought to play critical roles in both positioning 
the border of the neural plate during gastrulation and then also later in inducing migration of neural crest cells[125]. Cranial neural crest cells give rise the neurons and glia of the PNS and most of the cartilage, bone, and connective tissue of the face. The cartilage and bone forming properties of cranial neural crest cells distinguishes this population from trunk neural crest cells. Hence the cranial neural crest is a pluripotent population that is vital to vertebrate head development (Fig. 2)[126,127,128,129,130,131]. It is essential to understand the mechanisms by which cranial neural crest cells are patterned since many craniofacial malformations can be attributed to defects in the formation, proliferation, migration, and/or differentiation of this cell population.

The generation of regional diversity in the vertebrate head is believed to be a consequence of patterning information provided by neural crest cells during their migration and neural fold transplantation experiments have provided much of the basis for our current understanding of neural crest and craniofacial development[132,133,134,135,136]. First arch neural crest cells give rise to Meckel's cartilage, the articular, quadrate, and squamosal bones. In contrast the second arch neural crest cells develop into the hyoid or tongue cartilage and the retroarticular process $[9,136,137]$. In posterior transplantations of first arch (mandibular) neural crest primordia in place of second (hyoid) or third (visceral) arch neural crest, the transplanted neural crest cells migrated into the nearest arch but therein formed ectopic duplicated proximal first arch skeletal elements[136]. Not only were these duplicated crest-derived structures inappropriate for their new location but the muscle cell types and attachments associated with the duplicated structures were also characteristic of a first arch pattern. This suggested firstly that neural crest cell fate may be preprogrammed prior to their emigration from the neural tube and secondly, that myogenic populations and other cell types receive spatial cues from the invading neural crest-derived connective tissue. The vast majority of cranial neural crest cells are derived from the hindbrain and molecular evidence supporting this scenario was provided by the observation that the same restricted domains of Hox gene expression in the hindbrain are emulated in the migrating neural crest cells and then later in the ganglia and branchial arches, reflecting the origins of the neural crest cells contributing to these tissues[4,51]. Under this preprogramming model, it was thought that positional information encoded by the Hox genes was carried passively from the hindbrain to peripheral tissues and branchial arches by the neural crest, where it was elaborated to form the characteristic head structures. Therefore it was hypothesized that the spatial organization of structures within the vertebrate head was determined by the neural crest and furthermore that the positional information imparted by the neural crest was irreversibly set before the neural crest emigrates from the neural tube.

\section{CRANIAL NEURAL CREST PLASTICITY AND INDEPENDENT HOX GENE REGULATION MODEL}

The neural crest prepatterning model predicts that molecular and cellular alterations to the segmental organization of the hindbrain would have profound and detrimental consequences to craniofacial development via disruptions to the patterns of Hox gene expression and neural crest cell migration. The chick embryo has been the primary species for testing this model via rhombomere transplantations, rotations, and ablations owing to the ease of tissue manipulation in this species[112,138,139,140,141,142]. These analyses have yielded conflicting results regarding the degree of autonomy of Hox gene expression[143]. The recent application of techniques for transposing cells to the hindbrains of mouse[144] and zebrafish[145] embryos has significantly advanced our understanding of hindbrain and neural crest development. In the mouse, cells from $\mathrm{r} 3, \mathrm{r} 4$, or $\mathrm{r} 5$ were heterotopically grafted into $\mathrm{r} 2$. The majority of the transplanted cells remained as a cohort and maintained their Hox gene A-P identity. A few transplanted cells however, became separated from the primary graft and dispersed becoming intermingled with the 
neighboring populations. These cells consequently altered their identity in their new location by failing to maintain the Hox gene expression patterns characteristic of their origins, which is evidence for neuroepithelial plasticity. This implies that single or dispersed rhombomere cells respond and adapt to their new surrounding environments by altering their gene expression patterns because they lack the neighboring signals necessary to reinforce or maintain their original identity[144]. Similarly, single rhombomere cell transplantations in zebrafish provide further evidence for neural crest plasticity and the influence of cell community effects[145]. A complete switch in Hox gene expression patterns and ultimately cell fates occurred when single cells from $\mathrm{r} 2$ and $\mathrm{r} 6$ were reciprocally transplanted within the zebrafish hindbrain. This contrasts with the higher degrees of cell autonomy observed in chick embryo manipulations. It is important to note however that, in analyses performed in avian embryos, pairs of rhombomeres but generally much larger regions of the neural tube were being manipulated. It is not unreasonable to expect that cell community effects present in such large tissue grafts could account for the cell autonomy observed in these avian studies compared to the plasticity observed in mouse and zebrafish experiments where subrhombomeric or single cell populations were transplanted, respectively[143]. The degree of plasticity or autonomy is dependent upon not only the size of the graft but also the time at which the manipulations are carried out. During the later stages of hindbrain development, when morphological boundaries are established, rhombomere cells are much more likely to be irreversibly committed and maintain their Hox gene expression characteristics when transplanted to ectopic locations. Therefore one could argue that over time cells within the neural tube progressively lose responsiveness to the environmental signals that specify their segmental identities. Together these chick, mouse and fish studies highlight that cellcommunity effects and their associated signals are important for maintaining the axial identity of individual cells within the hindbrain.

These grafting experiments also revealed the absence of preprogramming in the character or fate of cranial neural crest cells. In heterotopic transpositions of cells within the mouse and zebrafish hindbrains, graft-derived neural crest cells migrated into the nearest branchial arch without any evidence of pathfinding or rerouting to their original axial level. Plasticity in Hox gene expression in mouse neural crest cells was evident by the complete down regulation of Hoxb1, Hoxb2, and Hoxa2 in these cells[144]. In zebrafish, experimental embryos raised to larval stages revealed that the transplanted cells differentiated and contributed to pharyngeal cartilages appropriate to their new A-P location[145]. Therefore these results show that the genetic and cellular A-P character of cranial neural crest cells are neither fixed nor passively transferred from the hindbrain to the branchial arches.

The neural plasticity described above correlates with molecular analyses that have identified distinct regulatory elements controlling Hox gene expression in different tissues such as the hindbrain and neural crest. Hoxa 2 is expressed in the hindbrain anteriorly up to the $\mathrm{r} 1 / 2$ boundary and in cranial neural crest cells that migrate into the second branchial arch[112]. Transgenic regulatory analyses of Hoxa 2 have revealed that multiple cis-acting elements are required independently for hindbrain and neural crest specific activity[55,146,147]. In r3 and r5, Hoxa 2 expression is directly regulated by the transcription factor Krox20[55]. In contrast, Hoxa2 expression in second branchial arch neural crest cells is tightly controlled by a number of elements, one of which binds to AP-2 family members. Mutation or deletion of this site in the Hoxa 2 enhancer abrogates expression in cranial neural crest cells but not in the hindbrain. These findings clearly demonstrate that at the molecular level, Hoxa 2 is independently regulated in rhombomeres and neural crest cells and this provides a mechanism for how neural crest cells can respond to the environment through which they migrate independently of the neural tube.

These experiments have revealed a surprising degree of plasticity in cranial neural crest cells, which is inconsistent with the prepatterning model. Since transposed neural crest can be reprogrammed it appears that crest cells rely on distinct cues in the branchial arch environments through which they migrate to elaborate their proper regional identity. Furthermore, the size of 


\section{Neural crest induction}

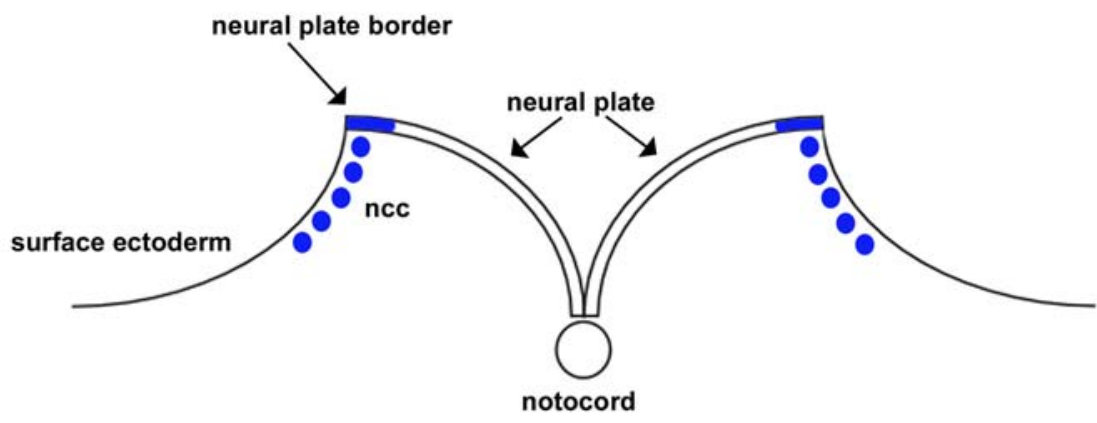

\section{Neural crest derivatives}

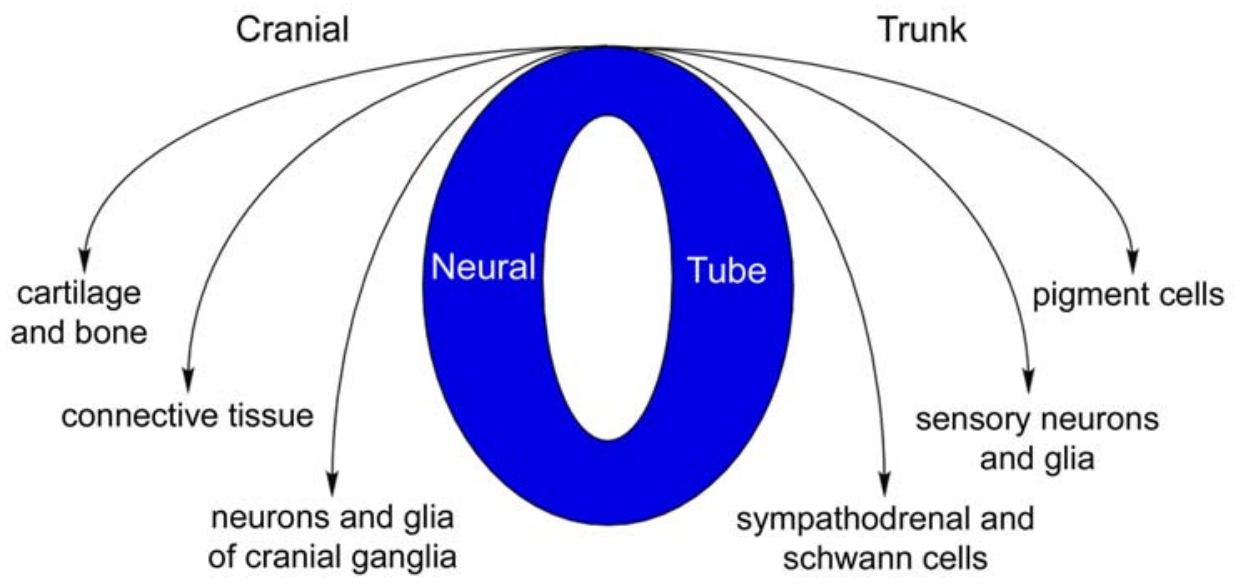

FIGURE 2. Neural crest cell induction and differentiation. Neural crest cells (ncc; blue circles) are induced at the neural plate border, which demarcates the junction between the neural plate and surface ectoderm. Both the neuroepithelium and the surface ectoderm gives rise to neural crest cells and contact between these tissues is essential for neural crest induction. In the mouse as depicted here, this occurs prior to closure of the neural tube. In contrast, in avian species the neural tube is closed prior to the emigration of neural crest cells. After migrating along stereotypic routes, the cranial neural crest cells differentiate into cartilage, bone, connective tissue as well as neurons and glia of the PNS. In contrast, trunk neural crest cells do not give rise to cartilage or bone rather they differentiate predominantly into the characteristic cells that constitute the trunk PNS.

the cell community is functionally important, indicating that a far more complex balance of genetic and cellular interactions are involved in hindbrain and neural crest patterning than was previously thought. The experiments described above therefore provide the basis for a new model, the neural crest plasticity and independent Hox gene regulation model which has been proposed as an alternative mechanism for governing neural crest and craniofacial development[143,144,148]. 


\section{EVOLUTION AND PATTERNING OF NEURAL CREST CELLS}

The classic neural crest preprogramming model implies that branchial arch formation and patterning is dependent upon the neural crest. In contrast, the neural crest plasticity and independent gene regulation model described above implies that branchial arch patterning arises due to interactions between the arch components and the neural crest. This raises the question of what happens to the formation and patterning of the branchial arches in the absence of contributing neural crest cells. This issue has been investigated in chick embryos through rhombomere ablations[149] and also mouse embryos by genetic manipulation of Hoxal and Hoxb1, which are required for the generation of neural crest cells in $\mathrm{r} 4$ [33]. In both experimental situations, despite the absence of any neural crest cell contribution, the branchial arches develop normally and are properly regionalized. The expression patterns of $B m p 7$ in the posterior endoderm, $\mathrm{Fg} f 8$ in the anterior surface ectoderm, Paxl in the pharyngeal pouch endoderm and Shh in the endoderm of the branchial arches were all normal and unchanged compared to wild type embryos. In addition there was no evidence for excessive cell death or loss of proliferation in the arch epithelium, which suggests that the neural crest cells are not the source of any indispensable branchial arch mitogenic or survival signals[33]. These results clearly demonstrate that the branchial arches are not dependent upon the neural crest for their formation, nor for their anterior-posterior and proximo-distal regionalization and hence this provides additional support for the neural crest plasticity and independent gene regulation model. This is also consistent with the evolutionary history of the branchial arches and neural crest cells. Pharyngeal segmentation is characteristic of the phylum chordata whereas neural crest cells are exclusively a craniate (vertebrates plus hagfish) characteristic[150], which implies that branchial arch segmentation occurred prior to the evolutionary origin of cranial neural crest cells. Hence it is not surprising that the branchial arches do not depend upon the cranial neural crest for their initial formation and regional specification. Additional support for this idea comes from the observation of regionalized domains of $\operatorname{Pax}$ gene expression in Amphioxus (the nearest extant vertebrate relative), which is indicative of pharyngeal segmentation. Amphioxus lack neural crest cells and therefore the mechanism for generating pharyngeal pouches clearly predates the evolution of the vertebrate head[151].

\section{PATTERNING ROLES FOR THE MESODERM, ENDODERM, AND ECTODERM IN BRANCHIAL ARCH DEVELOPMENT}

A crucial issue in craniofacial development is understanding the mechanisms that regulate the size and shapes of the characteristic facial skeletal structures and that branchial arch segmentation constitutes one of the first visible steps in this patterning process. Since normal branchial arch formation and patterning can occur independently of a contribution from the neural crest, this implies that the branchial arches may rely on either the endoderm, paraxial mesoderm, and/or the surface ectoderm tissues for their patterning information.

\section{The Mesoderm}

Fate mapping studies have shown that mesoderm and neural crest cells derived from the same axial level contribute to the same branchial arch during embryonic development (Fig. $3)[16,130,152,153]$. The cranial mesoderm predominantly gives rise to the myogenic cores of each branchial arch, which are enveloped by migrating neural crest cells[16,130,131,153,154]. Previously, the cranial mesoderm was not thought to play a patterning role during craniofacial development[136], however, it has now been shown that the cranial mesoderm provides 
maintenance signals for regulating the identity of second branchial arch neural crest cells[144] and that it may also play a role in patterning the pathways of neural crest cell migration (Fig. 3)[23]. When second arch neural crest cells are transplanted into the first arch, they downregulate their expression of Hoxb1. In contrast, if second arch neural crest cells are transplanted anteriorly in combination with second arch mesoderm, then Hoxbl expression is maintained in the grafted neural crest cells. The cranial mesoderm therefore provides maintenance signals that elaborate the programme of Hox expression, but the cranial mesoderm does not appear to initiate Hox gene expression in neural crest cells[144]. It is important to note however that Hoxbl is expressed in the cranial mesoderm at $7.5 \mathrm{dpc}$ prior to its induction in the neuroepithelium suggesting that perhaps the mesoderm is patterning neuroepithelial tissues at much earlier stages of development. The effects of the mesoderm are consistent with the fact that the fate of the cranial mesoderm is primarily myogenic and the musculature is inextricably linked to neural crest derived skeletal and connective tissue patterning. Therefore one of the roles of the cranial mesoderm maybe in maintaining an A-P register between these different primordial tissues, which is essential for subsequent craniofacial morphogenesis[16].

\section{The Ectoderm}

Similar to the neuroepithelium, it has been suggested that the ectoderm is regionalized into territories called ectomeres, which contribute to specific regions of the branchial arches (Fig. 3)[155]. Currently, there is no evidence to support the idea that each ectomere represents a functional developmental unit. In contrast, however, there is evidence suggesting that the surface ectoderm plays a major role in the induction of odontogenesis during branchial arch development[156]. The oral ectoderm of the first branchial arch directly regulates the patterning of the underlying neural crest mesenchyme into teeth and the ability to respond to these instructive or inducing signals is not confined to first arch neural crest cells[157]. Fgf8, which is expressed in the anterior surface ectoderm of the first arch, is essential for determining the polarity of the branchial arch and ectopic applications of FGF8 cause shifts in gene expression domains as well as repatterning of the craniofacial primordia[158]. Not surprisingly then, in $F g f 8$ null mutant mice, the branchial arches are severely abnormal[159]. Bmp4, which is expressed in the ventral region of the first branchial arch ectoderm, appears to restrict the expression domain of $F g f 8$ and consequently ectopic applications of BMP4 consistently reduce the size of the mandibular arch. Hence the surface ectoderm plays important roles in patterning the branchial arch derivatives particularly through the BMP4 and FGF8 signalling mechanisms (Fig. 3).

\section{The Endoderm}

The neurogenic placodes (dorsolateral and epibranchial) form in characteristic positions in all vertebrates suggesting that conserved localized inductive interactions underlie their formation[160]. The epibranchial placodes develop near the branchial clefts in close proximity to the cranial neural crest and the pharyngeal endoderm. Analyses of the nature of the signals, which underlie epibranchial placode formation, have found that the epibranchial placodes do not require cranial neural crest cells for their induction[161]. Rather, it is the pharyngeal endoderm that is the source of the BMP7 inducing signal. It has been suggested that neural crest cells will differentiate into cartilage only in the presence of pharyngeal endoderm and in amphibians, the endoderm has been shown to be responsible for promoting the formation of branchial arch components by directing neural crest cells towards a chondrogenic fate[162]. For example, in the zebrafish mutant van gogh (vgo), hindbrain segmentation occurs normally, but the endodermal gill slits do not form and the distinct streams of neural crest cells exiting from the hindbrain are fused. 
Consequently the individual skeletal elements of the viscerocranium do not form[163]. Therefore the endoderm plays a major role in establishing and patterning the branchial arches (Fig. 3). Recently the avian neural endoderm was tested in transplantation and ablation studies for its capacity to specify the facial skeleton[164]. The experiments suggested that the endoderm instructs neural crest cells as to the size, shape, and position of all the skeletal elements whether they are cartilaginous or membranous bones. In addition bone orientation was shown to be influenced by the position of the endoderm relative to the embryonic axes. The nature of the signals arising from the endoderm are so far unknown and it is not clear whether the effects of the endoderm manipulations are direct and intrinsic to the tissue itself or whether the effects of the manipulations indirectly alter local signaling centers or levels of FGF, Shh, or BMP which have been shown in other analyses to regulate the development of the characteristic craniofacial structures[159,165,166,167]. What is clear is that segmental characteristics of the endodermal pharyngeal pouches develop independently of a contribution of neural crest cells (Fig. 3)[149].

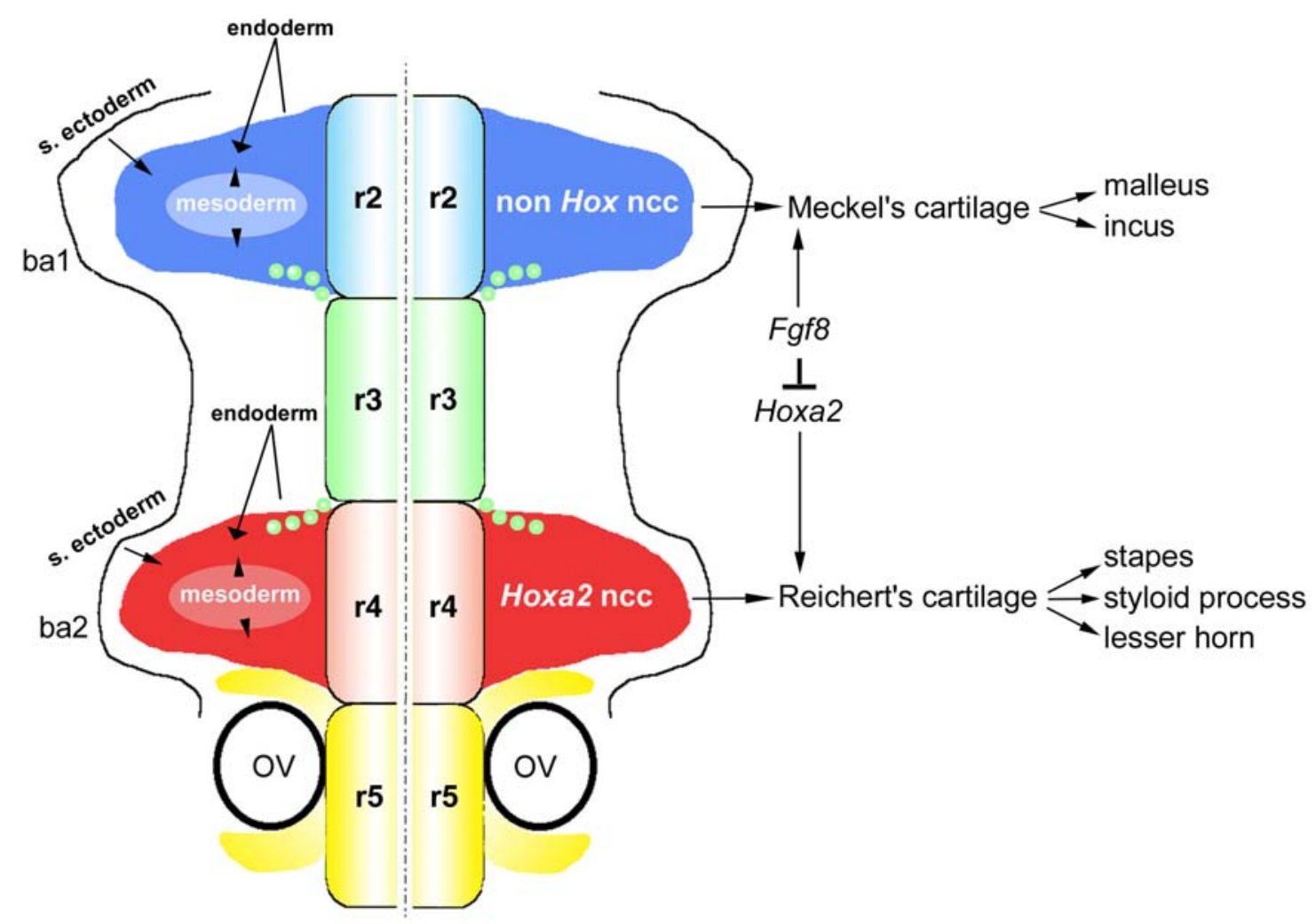

FIGURE 3. The influence of mesoderm, ectoderm, and endoderm on the axial identity of neural crest cells and the role of Hoxa2 in second branchial arch development. The head mesoderm (red and blue ovals) plays a role in maintaining the proper domains of $H o x$ gene expression in migrating neural crest cells $(\mathrm{ncc})$, whereas the ectoderm and endoderm play roles in possibly influencing the pathways of neural crest cell migration in addition to patterning the branchial arches. The skeletal derivatives arising from the first (ba1) and second (ba2) branchial arches are listed. Hoxa2 is expressed in neural crest cells migrating into the second arch but not the first arch acts and as a selector gene that imposes the unique identity of second arch structures. In the absence of Hoxa2, second arch derivatives are transformed into a first arch fate and similarly ectopic expression of Hoxa2 transforms first arch structures into a second arch identity. FGF8 has the capacity to repress Hoxa2 in second branchial arch neural crest cells, transforming the second arch into a first arch identity. OV, otic vesicle. 


\section{RESOLVING THE ISSUES OF NEURAL CREST PLASTICITY VS. PREPATTERNING AND SKELETAL DUPLICATIONS}

The analyses detailed above provide a wealth of evidence supporting the idea that cranial neural crest cells are not preprogrammed, but are in fact plastic and that they differentiate in response to signals from the environment through which they migrate. How then do we reconcile these findings with the skeletal duplications observed in posterior transplantations of presumptive first arch neural crest[136]? Two things are often ignored from this classic study. Firstly, in addition to forming duplicated first arch structures, the transplanted neural crest also contributed to the development of normal second arch skeletal elements including the paraglossals and basihyoid, which make up part of the tongue skeleton. This actually provides evidence for neural crest plasticity. Secondly, when presumptive frontonasal neural crest was grafted posteriorly in place of second arch neural crest, duplicated first arch skeletal elements (quadrate and proximal region of Meckel's cartilage) also developed, providing further evidence in support of neural crest plasticity[136]. It's important to note here that the same duplicated skeletal structures were formed regardless of the origin of the grafted neural crest cells.

What's intriguing about the skeletal duplications is that they phenocopy the Hoxa2 null mutant mouse in which the second arch is transformed into a first arch identity and one can speculate then that perhaps the landmark chick embryo manipulations were in effect creating a conditional knockout of Hoxa 2 in the second branchial arch. Recently, the isthmus was shown to inhibit Hoxa2 expression in rhombomere 1 via an FGF8 mediated signalling mechanism[168], and therefore one plausible explanation which could link the results of the two transplantations together is the possible inclusion of the isthmus in both the first arch and frontonasal neural crest grafts. This has now been tested directly via posterior transplantations of the isthmus in place of r4 that inhibits the expression of Hoxa2 in second branchial arch neural crest cells[169]. In the absence of Hoxa2 expression, as expected these grafted chick embryos develop duplicated first arch skeletal structures including the quadrate and proximal portion of Meckel's cartilage similar to the classic transplantations. FGF8 soaked beads can only transiently block Hoxa 2 expression in second branchial arch neural crest cells indicating that FGF8 cannot recapitulate the entire effects of the isthmus and that other genes/factors must be involved.

Therefore the possible inclusion of the isthmus in the transpositions and the ability of FGF8 to suppress Hoxa2 in second arch neural crest cells can account mechanistically for the development of duplicated first arch structures in ectopic posterior locations. Hence rather than providing evidence for neural crest preprogramming, Noden's 1983 experiments highlight the effects of local signaling centers like the isthmus in A-P patterning and regulation of Hox gene expression by FGFs[136]. Together with recent evidence from mouse, chick, and zebrafish transplantation studies, this argues as a general principle that cranial neural crest cells are not prespecified or irreversibly committed prior to their emigration from the neural tube. Rather, that neural crest patterning is based on plasticity and the ability of neural crest cells to respond to environmental signals and interactions with the tissues through which they migrate[144,148].

Recently inroads have been made into the mechanisms by which Hoxa2 influences the morphogenesis of second arch elements[170]. During normal development, Hoxa2 is widely expressed in the second arch mesenchyme, but it is excluded from the chondrogenic condensations in the core of the arches (Fig. 3). In the absence of Hoxa2, ectopic chondrogenesis occurs indicating that Hoxa 2 acts upstream very early in the chondrogenic pathway. In addition, Cbaf1, which is a marker of osteogenic differentiation, is upregulated in the second branchial arches of Hoxa 2 mutant embryos suggesting that the prevention of Cbfal induction might 
mediate Hoxa2 inhibition of dermal (intramembranous) bone formation during second arch development[170]. Therefore Hoxa 2 is essential for proper patterning of structures derived form the second branchial arch neural crest cells as it inhibits membranous ossification. Ectopic expression of Hoxa2 in the first arch of chick and Xenopus embryos results in the suppression of bone formation in the first arch and transformation of the first arch into second arch structures[171,172]. In the absence of Hoxa2 the second arch is transformed into a first arch identity and together these results indicate that Hoxa2 acts as a positive selector gene in specifying second branchial arch development and identity (Fig. 3).

\section{EVOLUTIONARY IMPORTANCE AND CONCLUSIONS}

Craniofacial evolution is considered fundamental to the origin of vertebrates and in evolutionary terms the vertebrate head is a relatively new structure[173]. This review has detailed the multiple levels of regulation and the diverse tissue interactions that are involved in generating the characteristic craniofacial features. Although the hindbrain exerts a profound influence in establishing the foundations of vertebrate head development, a rigid prepatterning model in which the programs for head morphogenesis were set in the hindbrain would however offer restricted opportunities for diversifying head structures[143,144,148]. In contrast the neural crest plasticity and independent gene regulation model could provide the flexibility and adaptability that facilitates diversity and we can speculate that it might be one reason for the successful radiation of vertebrates into new environments. This is because neural crest plasticity and independent gene regulation offers the potential for generating substantially distinct cranial phenotypes by minor changes of the primordial pattern. Future studies therefore will be focused on elucidating the mechanisms governing the formation and patterning of neural crest cells as they are critical to understanding craniofacial evolution and the origins of vertebrates.

\section{REFERENCES}

1. Vaage, S. (1969) The segmentation of the primitive neural tube in chick embryos (Gallus domesticus). Adv. Anat. Embryol. Cell Biol. 41, 1-88.

2. Wilkinson, D.G., Bhatt, S., Chavrier, P., Bravo, R., and Charnay, P. (1989) Segment-specific expression of a zinc finger gene in the developing nervous system of the mouse. Nature 337, 461-464.

3. Wilkinson, D. (1989) Homeobox genes and development of the vertebrate CNS. Bioessays 10, 82-85.

4. Hunt, P., Whiting, J., Muchamore, I., Marshall, H., and Krumlauf, R. (1991) Homeobox genes and models for patterning the hindbrain and branchial arches. Development 112(Suppl.), 187-196.

5. Fraser, S., Keynes, R., and Lumsden, A. (1990) Segmentation in the chick embryo hindbrain is defined by cell lineage restrictions. Nature 344, 431-435.

6. Birgbauer, E. and Fraser, S.E. (1994) Violation of cell lineage restriction compartments in the chick hindbrain. Development 120, 1347-1356.

7. Marín, F. and Puelles, L. (1995) Morphological fate of rhombomeres in quail/chick chimeras: a segmental analysis of hindbrain nuclei. Eur. J. Neurosci. 7, 1714-1738.

8. Wintgate, R. and Lumsden, A. (1996) Persistence of rhombomeric organisation in the postsegmental avian hindbrain. Development 122, 2143-2152.

9. Köntges, G. and Lumsden, A. (1996) Rhombencephalic neural crest segmentation is preserved throughout craniofacial ontogeny. Development 122, 3229-3242.

10. Lumsden, A. and Keynes, R. (1989) Segmental patterns of neuronal development in the chick hindbrain. Nature 337, 424-428. 
11. Clarke, J.D. and Lumsden, A. (1993) Segmental repetition of neuronal phenotype sets in the chick embryo hindbrain. Development 118, 151-162.

12. Sechrist, J., Serbedzija, G.N., Scherson, T., Fraser, S.E., and Bronner-Fraser, M. (1993) Segmental migration of the hindbrain neural crest does not arise from its segmental generation. Development 118(3), 691-703.

13. Lumsden, A., Sprawson, N., and Graham, A. (1991) Segmental origin and migration of neural crest cells in the hindbrain region of the chick embryo. Development 113, 1281-1291.

14. Serbedzija, G., Fraser, S., and Bronner-Fraser, M. (1992) Vital dye analysis of cranial neural crest cell migration in the mouse embryo. Development 116, 297-307.

15. Osumi-Yamashita, N., Ninomiya, Y., Doi, H., and Eto, K. (1994) The contribution of both forebrain and midbrain crest cells to the mesenchyme in the frontonasal mass of mouse embryos. Dev. Biol. 164, 409-419.

16. Trainor, P.A. and Tam, P.P.L. (1995) Cranial paraxial mesoderm and neural crest of the mouse embryocodistribution in the craniofacial mesenchyme but distinct segregation in the branchial arches. Development 121, 2569-2582.

17. Graham, A., Heyman, I., and Lumsden, A. (1993) Even-numbered rhombomeres control the apoptotic elimination of neural crest cells from odd-numbered rhombomeres in the chick hindbrain. Development 119, 233-245.

18. Graham, A., Francis-West, P., Brickell, P., and Lumsden, A. (1994) The signalling molecule BMP4 mediates apoptosis in the rhombencephalic neural crest. Nature 372, 684-686.

19. Ellies, D.L., Church, V., Francis-West, P., and Lumsden, A. (2000) The WNT antagonist cSFRP2 modulates programmed cell death in the developing hindbrain. Development 127, 5285-5295.

20. Schilling, T.F. and Kimmel, C.B. (1994) Segment and cell type lineage restrictions during pharyngeal arch development in the zebrafish embryo. Development 120, 483-494.

21. Kulesa, P. (1998) Neural crest cell dynamics revealed by time-lapse video microscopy of whole chick explant cultures. Dev. Biol. 204, 327-344.

22. Kulesa, P.M. and Fraser, S.E. (2000) In ovo time-lapse analysis of chick hindbrain neural crest cell migration shows cell interactions during migration to the branchial arches. Development 127, 1161-1172.

23. Trainor, P.A., Sobieszczuk, D., Wilkinson, D., and Krumlauf, R. (2002) Signalling between the hindbrain and paraxial tissues dictates neural crest migration pathways. Development 129, 433-442.

24. Lufkin, T., Dierich, A., LeMeur, M., Mark, M., and Chambon, P. (1991) Disruption of the Hox-1.6 homeobox gene results in defects in a region corresponding to its rostral domain of expression. Cell 66, $1105-1119$.

25. Chisaka, O., Musci, T., and Capecchi, M. (1992) Developmental defects of the ear, cranial nerves and hindbrain resulting from targeted disruption of the mouse homeobox gene Hox-1.6. Nature 355, 516-520.

26. Swiatek, P.J. and Gridley, T. (1993) Perinatal lethality and defects in hindbrain development in mice homozygous for a targeted mutation of the zinc finger gene Krox-20. Genes Dev. 7, 2071-2084.

27. Schneider-Maunoury, S., Topilko, P., Seitanidou, T., Levi, G., Cohen-Tannoudji, M., Pournin, S., Babinet, C., and Charnay, P. (1993) Disruption of Krox-20 results in alteration of rhombomeres 3 and 5 in the developing hindbrain. Cell 75, 1199-1214.

28. Gassmann, M., Casagranda, F., Orioli, D., Simon, H., Lai, C., Klein, R., and Lemke, G. (1995) Aberrant neural and cardiac development in mice lacking the ErbB4 neuregulin receptor. Nature 378, 390-394.

29. Meyer, D. and Birchmeier, C. (1995) Multiple essential functions of neuregulin in development. Nature 378, 386-390.

30. Goddard, J., Rossel, M., Manley, N., and Capecchi, M. (1996) Mice with targeted disruption of Hoxb1 fail to form the motor nucleus of the VIIth nerve. Development 122, 3217-3228.

31. Studer, M., Lumsden, A., Ariza-McNaughton, L., Bradley, A., and Krumlauf, R. (1996) Altered segmental identity and abnormal migration of motor neurons in mice lacking Hoxb-1. Nature 384, 630-635.

32. Manzanares, M., Trainor, P., Nonchev, S., Ariza-McNaughton, L., Brodie, J., Gould, A., Marshall, H., Morrison, A., Kwan, C.-T., Sham, M.-H., et al. (1999) The role of kreisler in segmentation during hindbrain development. Dev. Biol. 211, 220-237. 
33. Gavalas, A., Trainor, P., Ariza-McNaughton, L., and Krumlauf, R. (2001) Synergy between Hoxa1 and Hoxb1: the relationship between arch patterning and the generation of cranial neural crest. Development 128, $3017-3027$.

34. Guthrie, S. and Lumsden, A. (1991) Formation and regeneration of rhombomere boundaries in the developing chick hindbrain. Development 112, 221-229.

35. Guthrie, S., Prince, V., and Lumsden, A. (1993) Selective dispersal of avian rhombomere cells in orthotopic and heterotopic grafts. Development 118, 527-538.

36. Wizenmann, A. and Lumsden, A. (1997) Segregation of rhombomeres by differential chemoaffinity. Mol. Cell. Neurosci. 9, 448-459.

37. Wilkinson, D.G. (1995) Genetic control of segmentation in the vertebrate hindbrain. Perspect. Dev. Neurobiol. 3, 29-38.

38. Lumsden, A. and Krumlauf, R. (1996) Patterning the vertebrate neuraxis. Science 274, 1109-1115.

39. Trainor, P., Manzanares, M., and Krumlauf, R. (2000) Genetic interactions during hindbrain segmentation in the mouse embryo. In Mouse Brain Development: Results and Problems in Cell Differentiation. Vol. 30. Goffinet, A. and Rackic, P., Eds. Springer-Verlag, Berlin. pp. 51-89.

40. Wilkinson, D.G. (2001) Multiple roles of EPH receptors and ephrins in neural development. Nat. Rev. Neurosci. 2, 155-164.

41. Nieto, M.A., Gilardi-Hebenstreit, P., Charnay, P., and Wilkinson, D. (1992) A receptor protein tyrosine kinase implicated in the segmental patterning of the hindbrain and mesoderm. Development 116, 1137-1150.

42. Becker, N., Seitanidou, T., Murphy, P., Mattei, M.-G., Topilko, P., Nieto, M.A., Wilkinson, D.G., Charnay, P., and Gilardi-Hebenstreit, P. (1994) Several receptor tyrosine kinase genes of the Eph family are segmentally expressed in the developing hindbrain. Mech. Dev. 47, 3-18.

43. Gale, N.W., Holland, S.J., Valenzuela, D.M., Flenniken, A., Pan, L., Ryan, T.E., Henkemeyer, M., Strebhardt, K., Hirai, H., Wilkinson, D.G., et al. (1996) Eph receptors and ligands comprise two major specificity subclasses and are reciprocally compartmentalized during embryogenesis. Neuron 17, 9-19.

44. Xu, Q., Mellitzer, G., Robinson, V., and Wilkinson, D. (1999) In vivo cell sorting in complementary segmental domains mediated by Eph receptors and ephrins. Nature 399, 267-271.

45. Mellitzer, G., Xu, Q., and Wilkinson, D. (1999) Eph receptors and ephrins restrict cell intermingling and communication. Nature 400, 77-81.

46. McGinnis, W. and Krumlauf, R. (1992) Homeobox genes and axial patterning. Cell 68, 283-302.

47. Kappen, C., Schugart, K., and Ruddle, F. (1989) Two steps in the evolution of antennapedia-class vertebrate homeobox Genes. Proc. Natl. Acad. Sci. U. S. A. 86, 5459-5463.

48. Duboule, D. and Dolle, P. (1989) The structural and functional organization of the murine $H O X$ gene family resembles that of Drosophila homeotic genes. EMBO J. 8, 1497-1505.

49. Dollé, P., Izpisùa-Belmonte, J.C., Falkenstein, H., Renucci, A., and Duboule, D. (1989) Co-ordinate expression of the murine Hox-5 complex homeobox-containing genes during limb pattern formation. Nature 342, 767-772.

50. Kessel, M. and Gruss, P. (1991) Homeotic transformations of murine prevertebrae and concommitant alteration of Hox codes induced by retinoic acid. Cell 67, 89-104.

51. Hunt, P., Gulisano, M., Cook, M., Sham, M., Faiella, A., Wilkinson, D., Boncinelli, E., and Krumlauf, R. (1991) A distinct Hox code for the branchial region of the head. Nature 353, 861-864.

52. Wilkinson, D.G., Bhatt, S., Cook, M., Boncinelli, E., and Krumlauf, R. (1989) Segmental expression of Hox2 homeobox-containing genes in the developing mouse hindbrain. Nature 341, 405-409.

53. Frohman, M.A., Boyle, M., and Martin, G.R. (1990) Isolation of the mouse Hox-2.9 gene; analysis of embryonic expression suggests that positional information along the anterior-posterior axis is specified by mesoderm. Development 110, 589-607.

54. Murphy, P. and Hill, R.E. (1991) Expression of the mouse labial-like homeobox-containing genes, Hox 2.9 and Hox 1.6, during segmentation of the hindbrain. Development 111, 61-74. 
55. Nonchev, S., Vesque, C., Maconochie, M., Seitanidou, T., Ariza-McNaughton, L., Frain, M., Marshall, H., Sham, M.H., Krumlauf, R., Charnay, P. (1996) Segmental expression of Hoxa-2 in the hindbrain is directly regulated by Krox-20. Development 122, 543-554.

56. Sham, M.H., Vesque, C., Nonchev, S., Marshall, H., Frain, M., Das Gupta, R., Whiting, J., Wilkinson, D., Charnay, P., and Krumlauf, R. (1993) The zinc finger gene Krox-20 regulates Hoxb-2 (Hox2.8) during hindbrain segmentation. Cell 72, 183-196.

57. Maconochie, M., Nonchev, S., Studer, M., Chan, S.-K., Pöpperl, H., Sham, M.-H., Mann, R., and Krumlauf, R. (1997) Cross-regulation in the mouse HoxB complex: the expression of Hoxb2 in rhombomere 4 is regulated by Hoxb1. Genes Dev. 11, 1885-1896.

58. Manzanares, M., Cordes, S., Kwan, C.-T., Sham, M.-H., Barsh, G., and Krumlauf, R. (1997) Segmental regulation of Hoxb3 by kreisler. Nature 387, 191-195.

59. Manzanares, M., Cordes, S., Ariza-McNaughton, L., Sadl, V., Maruthainar, K., Barsh, G., and Krumlauf, R. (1999) Conserved and distinct roles of kreisler in regulation of the paralogous Hoxa3 and Hoxb3 genes. Development 126, 759-769.

60. Geada, A.M.C., Gaunt, S.J., Azzawi, M., Shimeld, S.M., Pearce, J., and Sharpe, P.T. (1992) Sequence and embryonic expression of the murine Hox-3.5 gene. Development 116, 497-506.

61. Morrison, A., Ariza-McNaughton, L., Gould, A., Featherstone, M., and Krumlauf, R. (1997) HOXD4 and regulation of the group 4 paralog genes. Development 124, 3135-3146.

62. Chavrier, P., Zerial, M., Lemaire, P., Almendral, J., Bravo, R., and Charnay, P. (1988) A gene encoding a protein with zinc fingers is activated during Go/G1 transition in cultured cells. EMBO J. 7, 29-35.

63. Lemaire, P., Revelant, O., Bravo, R., and Charnay, P. (1988) Two mouse genes encoding potential transcription factors with identical DNA-binding domains are activated by growth factors in cultured cells. Proc. Natl. Acad. Sci. U. S. A. 85, 4691-4695.

64. Nardelli, J., Gibson, T., Vesque, C., and Charnay, P. (1991) Base sequence discrimination by zinc-finger DNA-binding domains. Nature 349, 175-178.

65. Deol, M.S. (1964) The origin of the abnormalities of the inner ear in dreher mice. J. Embryol. Exp. Morphol. 12, 727-733.

66. Cordes, S.P. and Barsh, G.S. (1994) The mouse segmentation gene $k r$ encodes a novel basic domain-leucine zipper transcription factor. Cell 79, 1025-1034.

67. Conlon, R.A. and Rossant, J. (1992) Exogenous retinoic acid rapidly induces anterior ectopic expression of murine Hox-2 genes in vivo. Development 116, 357-368.

68. Conlon, R.A. (1995) Retinoic acid and pattern formation in vertebrates. TIG 11, 314-319.

69. Morriss, G.M. and Thorogood, P.V. (1978) An approach to cranial neural crest migration and differentiation in mammalian embryos. In Development in Mammals. Johnson, M.H., Ed. Elsevier/North-Holland, Amsterdam. pp. 363-411.

70. Lammer, E., Chen, D., Hoar, R., Agnish, A., Benke, P., Braun, J., Curry, C., Fernhoff, P., Grix, A., Lott, I., et al. (1985) Retinoic acid embryopathy. N. Engl. J. Med. 313, 837-841.

71. Durston, A., Timmermans, J., Hage, W., Hendriks, H., de Vries, N., Heideveld, M., and Nieuwkoop, P. (1989) Retinoic acid causes an anteroposterior transformation in the developing central nervous system. Nature 340, 140-144.

72. Marshall, H., Nonchev, S., Sham, M.H., Muchamore, I., Lumsden, A., and Krumlauf, R. (1992) Retinoic acid alters hindbrain Hox code and induces transformation of rhombomeres $2 / 3$ into a $4 / 5$ identity. Nature 360, 737-741.

73. Mangelsdorf, D.J., Thummel, C., Beato, M., Herrlich, P., Schütz, G., Umesono, K., Blumberg, B., Kastner, P., Mark, M., Chambon, P., et al. (1995) The nuclear receptor superfamily: the second decade. Cell 83, 835-839.

74. Dencker, L., Annerwall, E., Busch, C., and Eriksson, U. (1990) Localization of specific retinoid-binding sites and expression of cellular retinoic-acid-binding protein (CRABP) in the early mouse embryo. Development 110, 343-352.

75. Maden, M., Horton, C., Graham, A., Leonard, L., Pizzey, J., Siegenthaler, G., Lumsden, A., and Eriksson, U. (1992) Domains of cellular retinoic acid-binding protein I (CRABP I) expression in the hindbrain and neural crest of the mouse embryo. Mech. Dev. 37, 13-23. 
76. Ruberte, E., Friederich, V., Morriss-Kay, G., and Chambon, P. (1992) Differential distribution patterns of CRABP-I and CRABP-II transcripts during mouse embryogenesis. Development 115, 973-989.

77. Lyn, S. and Giguere, V. (1994) Localisation of CRABP-I and CRABP-II mRNA in the early mouse embryo by whole-mount in situ hybridisation: implications for teratogenesis and neural development. Dev. Dynam. 199, 280-291.

78. Mangelsdorf, D.J., Borgmeyer, U., Heyman, R.A., Yang Zhou, J., Ong, E.S., Oro, A.E., Kakizuka, A., and Evans, R.M. (1992) Characterization of three RXR genes that mediate the action of 9-cis retinoic acid. Genes Dev. 6, 329-344.

79. Mangelsdorf, D.J. and Evans, R.M. (1995) The RXR heterodimers and ophan receptors. Cell 83, 841-850.

80. Mendelsohn, C., Larkin, S., Mark, M., LeMeur, M., Clifford, J., Zelent, A., and Chambon, P. (1994) RAR-isoforms: distinct transcriptional control by retinoic acid and specific spatial patterns of promoter activity during mouse embryonic development. Mech. Dev. 45, 227-241.

81. Mendelsohn, C., Ruberte, E., Le Meur, M., Morriss-Kay, G., and Chambon, P. (1991) Developmental analysis of the retinoic acid-inducible RAR-beta 2 promoter in transgenic animals. Development 113, 723734.

82. Dollé, P., Ruberte, E., Leroy, P., Morriss-Kay, G., and Chambon, P. (1990) Retinoic acid receptors and cellular retinoid binding proteins. I. A systematic study of their differential pattern of transcription during mouse organogenesis. Development 110, 1133-1151.

83. Dollé, P., Fraulob, V., Kastner, P., and Chambon, P. (1994) Developmental expression of murine retinoid X receptor (RXR) genes. Mech. Dev. 45, 91-104.

84. Simeone, A., Acampora, D., Arcioni, L., Andrews, P.W., Boncinelli, E., and Mavilio, F. (1990) Sequential activation of HOX2 homeobox genes by retinoic acid in human embryonal carcinoma cells. Nature 346, $763-766$.

85. Simeone, A., Acampora, D., Nigro, V., Faiella, A., D'Esposito, M., Stornaiuolo, A., Mavilio, F., and Boncinelli, E. (1991) Differential regulation by retinoic acid of the homeobox genes of the four HOX loci in human embryonal carcinoma cells. Mech. Dev. 33, 215-227.

86. Papalopulu, N., Hunt, P., Wilkinson, D., Graham, A., and Krumlauf, R. (1990) Hox-2 homeobox genes and retinoic acid: potential roles in patterning the vertebrate nervous system. In Advances in Neural Regeneration Research. Seil, F.J., Ed. Wiley-Liss, New York. pp. 291-307.

87. Papalopulu, N., Clarke, J., Bradley, L., Wilkinson, D., Krumlauf, R., and Holder, N. (1991) Retinoic acid causes abnormal development and segmental patterning of the anterior hindbrain in Xenopus embryos. Development 113, 1145-1159.

88. Moroni, M., Vigano, M., and Mavilio, F. (1993) Regulation of the human HOXD4 gene by retinoids. Mech. Dev. 44, 139-154.

89. Hill, J., Clarke, J.D.W., Vargesson, N., Jowett, T., and Holder, N. (1995) Exogenous retinoic acid causes specific alterations in the development of the midbrain and hindbrain of the zebrafish embryo including positional respecification of the Mauthner neuron. Mech. Dev. 50, 3-16.

90. Papalopulu, N. and Kintner, C. (1996) A posteriorising factor, retinoic acid, reveals that anteroposterior patterning controls the timing of neuronal differentiation in Xenopus neuroectoderm. Development 122, 3409-3418.

91. Morrison, A., Chaudhuri, C., Ariza-McNaughton, L., Muchamore, I., Kuroiwa, A., and Krumlauf, R. (1995) Comparative analysis of chicken Hoxb-4 regulation in transgenic mice. Mech. Dev. 53, 47-59.

92. Morrison, A., Moroni, M., Ariza-McNaughton, L., Krumlauf, R., and Mavilio, F. (1996) In vitro and transgenic analysis of a human HOXD4 retinoid-responsive enhancer. Development 122, 1895-1907.

93. Kolm, P. and Sive, H. (1995) Regulation of the Xenopus labial homeodomain genes, HoxA1 and HoxD1: activation by retinoids and peptide growth factors. Dev. Biol. 167, 34-49.

94. Kolm, P., Apekin, V., and Sive, H. (1997) Xenopus hindbrain patterning requires retinoid signaling. Dev. Biol. 192, 1-16.

95. Blumberg, B., Bolado, J., Moreno, T., Kintner, C., Evans, R., and Papalopulu, N. (1997) An essential role for retinoid signaling in anteroposterior neural patterning. Development 124, 373-379. 
96. Sharpe, C. and Goldstone, K. (1997) Retinoid receptors promote primary neurogenesis in Xenopus. Development 124, 515-523.

97. Langston, A.W. and Gudas, L.J. (1992) Identification of a retinoic acid responsive enhancer 3' of the murine homeobox gene Hox-1.6. Mech. Dev. 38, 217-228.

98. Pöpperl, H. and Featherstone, M. (1993) Identification of a retinoic acid repsonse element upstream of the murine Hox-4.2 gene. Mol. Cell. Biol. 13, 257-265.

99. Marshall, H., Studer, M., Pöpperl, H., Aparicio, S., Kuroiwa, A., and Brenner, S., Krumlauf, R. (1994) A conserved retinoic acid response element required for early expression of the homeobox gene Hoxb-1. Nature 370, 567-571.

100. Studer, M., Pöpperl, H., Marshall, H., Kuroiwa, A., and Krumlauf, R. (1994) Role of a conserved retinoic acid response element in rhombomere restriction of Hoxb-1. Science 265, 1728-1732.

101. Gould, A., Itasaki, N., and Krumlauf, R. (1998) Initiation of rhombomeric Hoxb4 expression requires induction by somites and a retinoid pathway. Neuron 21, 39-51.

102. Huang, D., Chen, S., langston, A., and Gudas, L. (1998) A conserved retinoic acid responsive element in the murine Hoxb-1 gene is required for expression in the developing gut. Development 125, 3235-3246.

103. Packer, A., Crotty, D., Elwell, V., and Wolgemuth, D. (1998) Expression of the murine Hoxa4 gene requires both autoregulation and a conserved retinoic acid response element. Development 125, 1991-1998.

104. Moallem, S.A. and Hales, B.F. (1995) Induction of apoptosis and cathepsin D in limbs exposed in vitro to an activated analog of cyclophosphamide. Teratology 52, 3-14.

105. Pöpperl, H., Bienz, M., Studer, M., Chan, S., Aparicio, S., Brenner, S., Mann, R., and Krumlauf, R. (1995) Segmental expression of Hoxb1 is controlled by a highly conserved autoregulatory loop dependent upon exd/Pbx. Cell 81, 1031-1042.

106. Gould, A., Morrison, A., Sproat, G., White, R., and Krumlauf, R. (1997) Positive cross-regulation and enhancer sharing: two mechanisms for specifying overlapping Hox expression patterns. Genes Dev 11, 900913.

107. Zhang, M., Kim, H.-J., Marshall, H., Gendron-Maguire, M., Lucas, A.D., Baron, A., Gudas, L.J., Gridley, T., Krumlauf, R., and Grippo, J.F. (1994) Ectopic Hoxa-1 induces rhombomere transformation in mouse hindbrain. Development 120, 2431-2442.

108. Alexandre, D., Clarke, J., Oxtoby, E., Yan, Y.-L., Jowett, T., and Holder, N. (1996) Ectopic expression of Hoxa-1 in the zebrafish alters the fate of the mandibular arch neural crest and phenocopies a retinoic acid induced phenotype. Development 122, 735-746.

109. Bell, E., Wingate, R., and Lumsden, A. (1999) Homeotic transformation of rhombomere identity after localized Hoxb1 misexpression. Science 284, 2168-2171.

110. Gavalas, A., Studer, M., Lumsden, A., Rijli, F., Krumlauf, R., and Chambon, P. (1998) Hoxal and Hoxb1 synergize in patterning the hindbrain, cranial nerves and second pharyngeal arch. Development 125, 11231136.

111. Studer, M., Gavalas, A., Marshall, H., Ariza-McNaughton, L., Rijli, F., Chambon, P., and Krumlauf, R. (1998) Genetic interaction between Hoxal and Hoxbl reveal new roles in regulation of early hindbrain patterning. Development 125, 1025-1036.

112. Prince, V. and Lumsden, A. (1994) Hoxa-2 expression in normal and transposed rhombomeres: independent regulation in the neural tube and neural crest. Development 120, 911-923.

113. Rijli, F.M., Mark, M., Lakkaraju, S., Dierich, A., Dolle, P., and Chambon, P. (1993) A homeotic transformation is generated in the rostral branchial region of the head by disruption of Hoxa-2, which acts as a selector gene. Cell 75, 1333-1349.

114. Bailey, W.J., Kim, J., Wagner, G.P., and Ruddle, F.H. (1997) Phylogenetic reconstruction of vertebrate Hox cluster duplications. Mol. Biol. Evol. 14, 843-853.

115. Davenne, M., Maconochie, M., Neun, R., Brunet, J.-F., Chambon, P., Krumlauf, R., and Rijli, F. (1999) Hoxa2 and Hoxb2 control dorsoventral patterns of neuronal development in the rostral hindbrain. Neuron 22, 677-691.

116. Chisaka, O. and Capecchi, M. (1991) Regionally restricted developmental defects resulting from targeted disruption of the mouse homeobox gene hox1.5. Nature 350, 473-479. 
117. Manley, N. and Capecchi, M. (1997) Hox group 3 paralogous genes act synergistically in the formation of somitic and neural crest-derived structures. Dev. Biol. 192, 274-288.

118. Condie, B. and Capecchi, M. (1993) Mice homozygous for a targeted disruption of Hoxd-3(Hox-4.1) exhibit anterior transformations of the first and second cervical vertebrae, the atlas and axis. Development 119, 579-595.

119. Condie, B.G. and Capecchi, M.R. (1994) Mice with targeted disruptions in the paralogous genes Hoxa-3 and Hoxd-3 reveal synergistic interactions. Nature 370, 304-307.

120. Manley, N. and Capecchi, M. (1998) Hox group 3 paralogs regulate the development and migration of the thymus, thyroid and parathyroid glands. Dev. Biol. 195, 1-15.

121. Schneider-Maunoury, S., Seitanidou, T., Charnay, P., and Lumsden, A. (1997) Segmental and neuronal architecture of the hindbrain of Krox-20 mouse mutants. Development 124, 1215-1226.

122. Frohman, M.A., Martin, G.R., Cordes, S., Halamek, L.P., and Barsh, G.S. (1993) Altered rhombomerespecific gene expression and hyoid bone differentiation in the mouse segmentation mutant kreisler $(\mathrm{kr})$. Development 117, 925-936.

123. Theil, T., Ariza-McNaughton, L., Manzanares, M., Krumlauf, R., and Wilkinson, D. (1999) kreisler regulates rostrocaudal identity in the hindbrain. Development, in revision.

124. Selleck, M.A. and Bronner-Fraser, M. (1995) Origins of the avian neural crest: the role of neural plateepidermal interactions. Development 121, 525-538.

125. Liem, K.F., Jr., Tremml, G., Roelink, H., and Jessell, T.M. (1995) Dorsal differentiation of neural plate cells induced by BMP-mediated signals from epidermal ectoderm. Cell 82, 969-979.

126. Le Douarin, N.M., Ziller, C., and Couly, G.F. (1993) Patterning of neural crest derivatives in the avian embryo: in vivo and in vitro studies. Dev. Biol. 159, 24-49.

127. Le Douarin, N. and Kalcheim, C. (1999) The Neural Crest. $2^{\text {nd }}$ ed. Bard, J., Barlow, P., and Kirk, D., Eds. Cambridge Univesity Press, U.K.

128. Noden, D. (1978) The control of avian cephalic neural crest cytodifferentiation. I. Skeletal and connective tissues. Dev. Biol. 67, 296-312.

129. Noden, D. (1978) The control of avian cephalic neural crest cytodifferentiation. II. Neural tissues. Dev. Biol. 67, 313-329.

130. Noden, D. (1988) Interactions and fates of avian craniofacial mesenchyme. Development 103, 121-140.

131. Noden, D.M. (1986) Origins and patterning of craniofacial mesenchymal tissues. J. Craniofacial Genet. Dev. Biol. (Suppl. 2), 15-31.

132. Andres, G. (1946) Uber Induction und Entwicklung von Kopforganen aus Unkenektoderm im Molch (Epidermis, Plakoden and Derivate der Nemalleiste). Rev. Suisse Zool. 53, 502-510.

133. Andres, G. (1949) Untersuchungen an chimaren von Triton und Bombinator. Genetics 24, 387-534.

134. Wagner, G. (1949) Die Bedeutung der Neualleiste fur die Kpfgestaltung der Amphibienlarven. Rev. Suisse Zool. 56, 519-620.

135. Wagner, G. (1959) Untersuchungen an Bombinator-Triton-Chimareren. Rouux Arch. Entwicklungsmech. 151, 136-158.

136. Noden, D. (1983) The role of the neural crest in patterning of avian cranial skeletal, connective, and muscle tissues. Dev. Biol. 96, 144-165.

137. Couly, G. and LeDouarin, N. (1988) The fate map of cephalic neural primordium at the presomitic to the 3somtie stage in the avian embryo. Development 103(Suppl.), 101-113.

138. Saldivar, J., Krull, C., Krumlauf, R., Ariza-McNaughton, L., and Bronner-Fraser, M. (1996) Rhombomere of origin determines autonomous versus environmentally regulated expression of Hoxa3 in the avian embryo. Development 122, 895-904.

139. Hunt, P., Ferretti, P., Krumlauf, R., and Thorogood, P. (1995) Restoration of normal Hox code and branchial arch morphogenesis after extensive deletion of hindbrain neural crest. Dev. Biol. 168, 584-597.

140. Hunt, P., Clarke, J.D.W., Buxton, P., Ferretti, P., and Thorogood, P. (1998) Stability and plasticity of neural crest patterning and branchial arch Hox code after extensive cephalic crest rotation. Dev. Biol. 198, 82-104. 
141. Grapin-Botton, A., Bonnin, M.-A., Ariza-McNaughton, L., Krumlauf, R., and LeDouarin, N.M. (1995) Plasticity of transposed rhombomeres: Hox gene induction is correlated with phenotypic modifications. Development 121, 2707-2721.

142. Couly, G., Grapin-Botton, A., Coltey, P., Ruhin, B., and Le Douarin, N.M. (1998) Determination of the identity of the derivatives of the cephalic neural crest: incompatibility between Hox gene expression and lower jaw development. Development 128, 3445-3459.

143. Trainor, P. and Krumlauf, R. (2000) Patterning the cranial neural crest: Hindbrain segmentation and Hox gene pasticity. Nat. Rev. Neurosci. 1, 116-124.

144. Trainor, P. and Krumlauf, R. (2000) Plasticity in mouse neural crest cells reveals a new patterning role for cranial mesoderm. Nat. Cell Biol. 2, 96-102.

145. Schilling, T. (2001) Plasticity of zebrafish Hox expression in the hindbrain and cranial neural crest hindbrain. Dev. Biol. 231, 201-216.

146. Maconochie, M., Krishnamurthy, R., Nonchev, S., Meier, P., Manzanares, M., Mitchell, P., and Krumlauf, R. (1999) Regulation of Hoxa2 in cranial neural crest cells involves members of the $A P-2$ family. Development 126, 1483-1494.

147. Frasch, M., Chen, X., and Lufkin, T. (1995) Evolutionary-conserved enhancers direct region-specific expression of the murine Hoxa-1 and Hoxa-2 loci in both mice and Drosophila. Development 121, 957-974.

148. Trainor, P.A. and Krumlauf, R. (2001) Hox genes, neural crest cells and branchial arch patterning. Curr. Opin. Cell Biol. 13, 698-705.

149. Veitch, E., Begbie, J., Schilling, T.F., Smith, M.M., and Graham, A. (1999) Pharyngeal arch patterning in the absence of neural crest. Curr. Biol. 9, 1481-1484.

150. Schaeffer, B. (1987) Deutoerstome monophyly and phylogeny. Evol. Biol. 21, 179-234.

151. Holland, P.W.H. and Garcia-Fernandez, J. (1996) Hox genes and chordate evolution. Dev. Biol. 173, 382395.

152. Noden, D.M. (1982) Patterns and organization of craniofacial skeletogenic and myogenic mesenchyme: a perspective. Prog. Clin. Biol. Res. 101, 167-203.

153. Noden, D. (1987) Interactions between cephalic neural crest and mesodermal populations. In Developmental and Evolutionary Aspects of the Neural Crest. Maderson, P.F.A., Ed. John Wiley \& Sons, New York. pp. 89-119.

154. Trainor, P.A., Tan, S.S., and Tam, P.P.L. (1994) Cranial paraxial mesoderm-regionalization of cell fate and impact on craniofacila development in mouse embryos. Development 120, 2925-2932.

155. Couly, G. and Le Douarin, N. (1990) Head morphogenesis in embryonic avian chimeras: evidence for a segmental pattern in the ectoderm corresponding to the neuromeres. Development 108, 543-558.

156. Lumsden, A.G. (1988) Spatial organization of the epithelium and the role of neural crest cells in the initiation of the mammalian tooth germ. Development 103(Suppl.), 155-169.

157. Tucker, A.S. and Sharpe, P.T. (1999) Molecular genetics of tooth morphogenesis and patterning: the right shape in the right place. J. Dent. Res. 78, 826-834.

158. Tucker, A.S., Yamada, G., Grigoriou, M., Pachnis, V., and Sharpe, P.T. (1999) Fgf-8 determines rostralcaudal polarity in the first branchial arch. Development 126, 51-61.

159. Trumpp, A., Depew, M.J., Rubenstein, J.L., Bishop, J.M., and Martin, G.R. (1999) Cre-mediated gene inactivation demonstrates that FGF8 is required for cell survival and patterning of the first branchial arch. Genes Dev. 13, 3136-3148.

160. Baker, C.V. and Bronner-Fraser, M. (2001) Vertebrate cranial placode. I. Embryonic induction. Dev. Biol. 232, 1--61.

161. Begbie, J., Brunet, J.F., Rubenstein, J.L., and Graham, A. (1999) Induction of the epibranchial placodes. Development 126, 895-902.

162. Epperlein, H.H. (1974) The ectomesenchymal-endodermal interaction-system (EEIS) of Triturus alpestris in tissue culture. I. Observations on attachment, migration and differentiation of neural crest cells. Differentiation 2, 151-168. 
163. Piotrowski, T. and Nusslein-Volhard, C. (2000) The endoderm plays an important role in patterning the segmented pharyngeal region in zebrafish (Danio rerio). Dev. Biol. 225, 339-356.

164. Couly, G., Creuzet, S., Bennaceur, S., Vincent, C., and Le Douarin, N.M. (2002) Interactions between Hoxnegative cephalic neural crest cells and the foregut endoderm in patterning the facial skeleton in the vertebrate head. Development 129, 1061-1073.

165. Lee, S.H., Fu, K.K., Hui, J.N., and Richman, J.M. (2001) Noggin and retinoic acid transform the identity of avian facial prominences. Nature 414, 909-912.

166. Hu, D. and Helms, J.A. (1999) The role of sonic hedgehog in normal and abnormal craniofacial morphogenesis. Development 126, 4873-4884.

167. Barlow, A.J. and Francis-West, P.H. (1997) Ectopic application of recombinant BMP-2 and BMP-4 can change patterning of developing chick facial primordia. Development 124, 391-398.

168. Irving, C. and Mason, I. (2000) Signalling by fgf8 from the isthmus patterns the anterior hindbrain and establishes the anterior limit of Hox gene expression. Development 127, 177-186.

169. Trainor, P.A., Ariza-McNaughton, L., and Krumlauf, R. (2002) Role of the isthmus and FGFs in resolving the paradox of neural crest plasticity and prepatterning. Science 295, 1288-1291.

170. Kanzler, B., Kuschert, S.J., Liu, Y.-H., and Mallo, M. (1998) Hoxa2 restricts the chondrogenic domain and inhibits bone formation during development of the branchial area. Development 125, 2587-2597.

171. Grammatopoulos, G.A., Bell, E., Toole, L., Lumsden, A., and Tucker, A.S. (2000) Homeotic transformation of branchial arch identity after Hoxa2 overexpression. Development 127, 5355-5365.

172. Pasqualetti, M., Ori, M., Nardi, I., and Rijli, F.M. (2000) Ectopic Hoxa2 induction after neural crest migration results in homeosis of jaw elements in Xenopus. Development 127, 5367-5378.

173. Gans, C. and Northcutt, R. (1983) Neural crest and the origin of vertebrates: a new head. Science 220, 268274.

\section{This article should be referenced as follows:}

Trainor, Paul A. (2003) Making headway: The roles of Hox genes and neural crest cells in craniofacial development. TheScientificWorldJOURNAL 3, 240-264.

\section{Handling Editor:}

Roger Keynes, Principal Editor for Embryology — a domain of TheScientificWorldJOURNAL. 

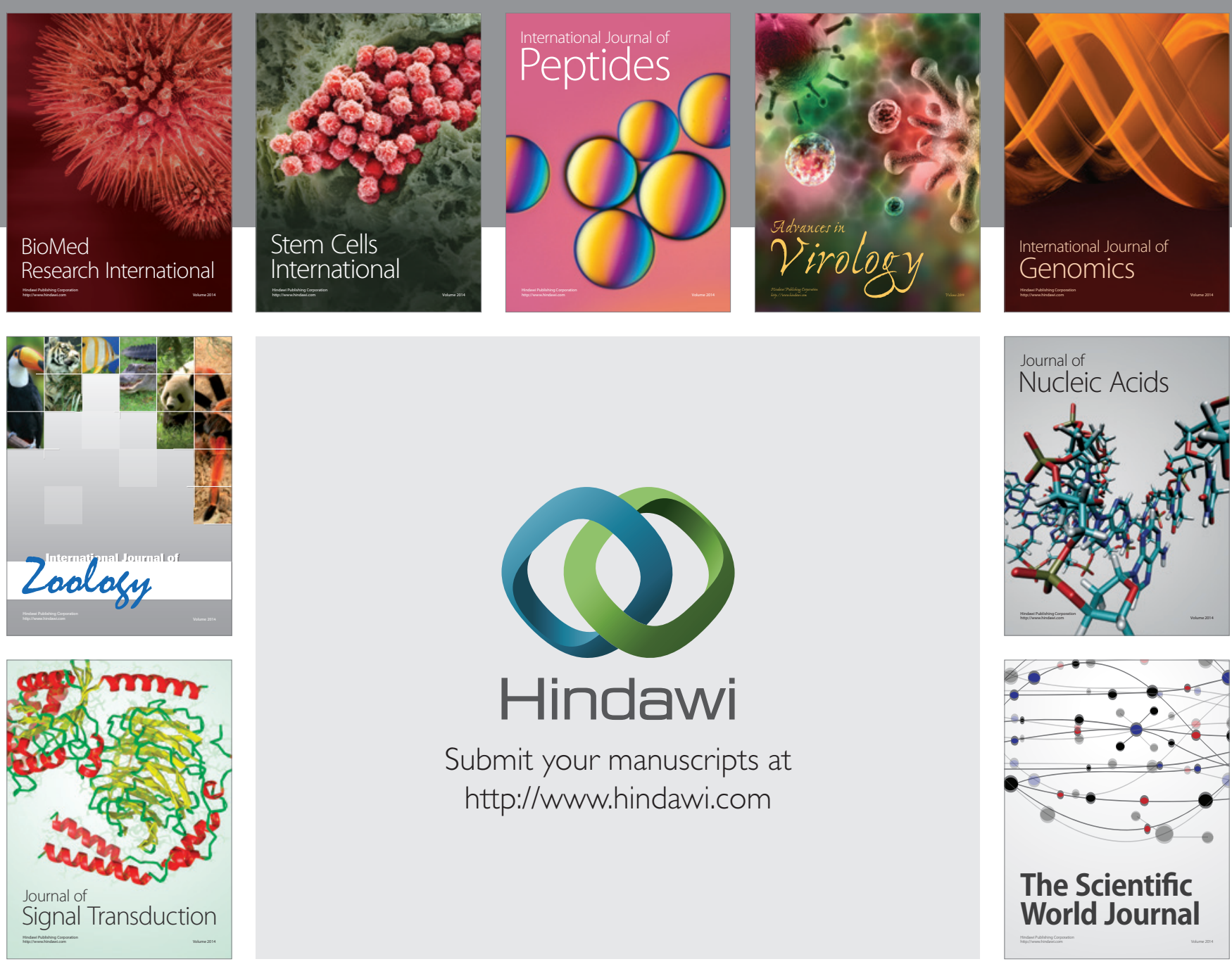

Submit your manuscripts at

http://www.hindawi.com
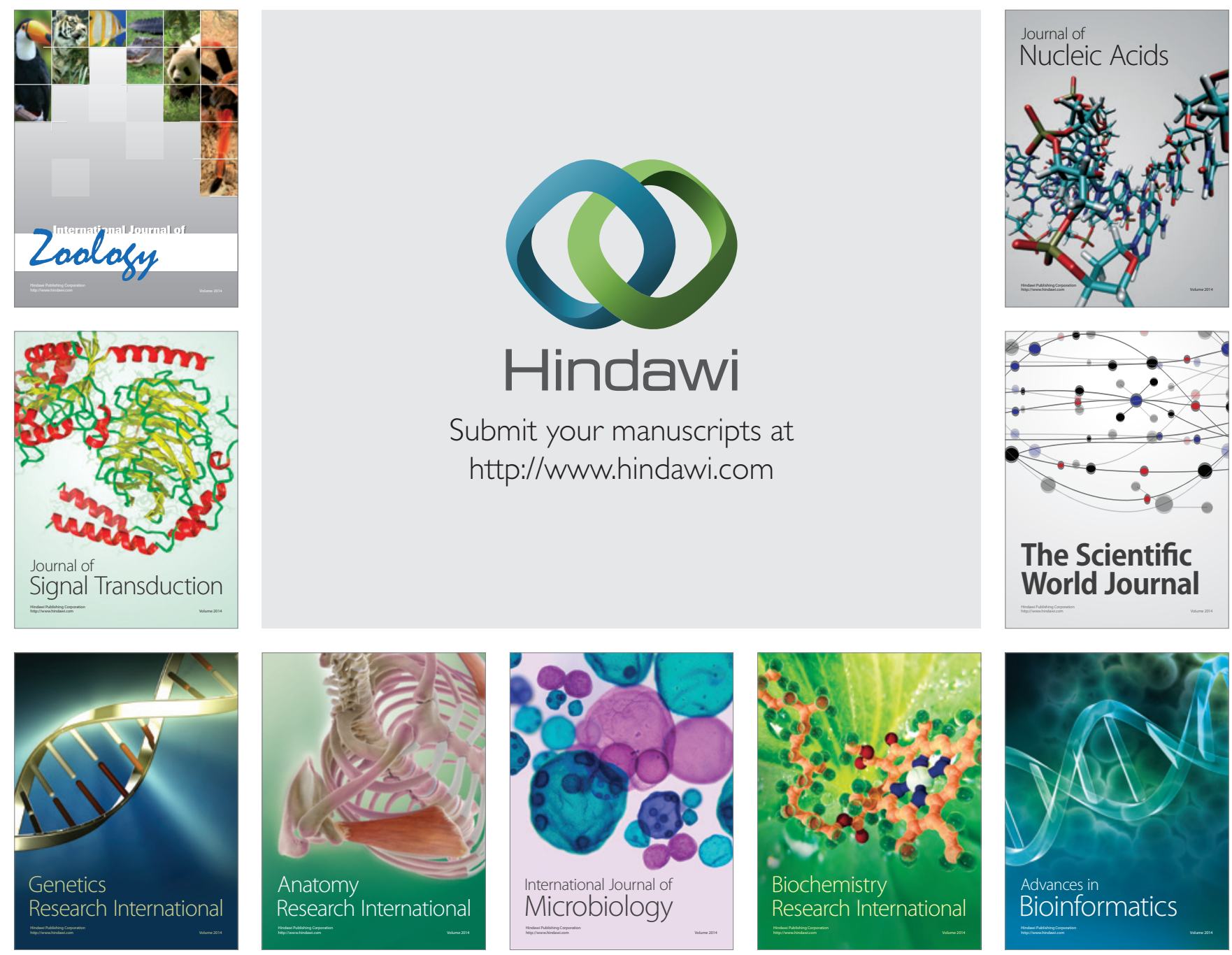

The Scientific World Journal
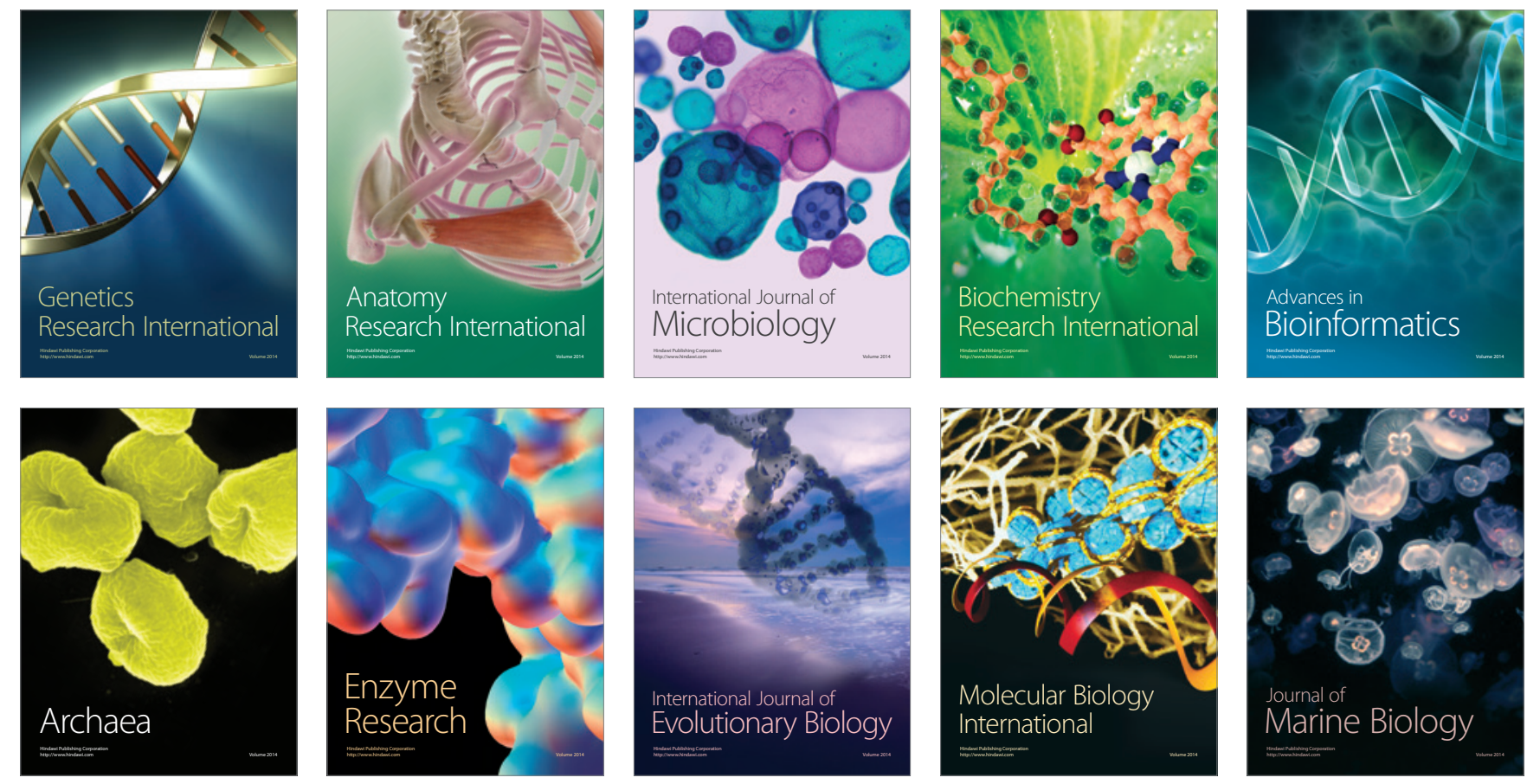